\title{
Validation and comparison of two soil-vegetation-atmosphere transfer models for tropical Africa
}

\author{
T. Akkermans, ${ }^{1}$ D. Lauwaet, ${ }^{1,2}$ M. Demuzere, ${ }^{1}$ G. Vogel,${ }^{3}$ Y. Nouvellon, ${ }^{4,5,6}$ J. Ardö, ${ }^{7}$ \\ B. Caquet, ${ }^{4,5}$ A. De Grandcourt, ${ }^{4,5}$ L. Merbold, ${ }^{8}$ W. Kutsch, ${ }^{9}$ and N. Van Lipzig ${ }^{1}$
}

Received 13 July 2011; revised 10 February 2012; accepted 18 February 2012; published 8 May 2012.

[1] This study aims to compare and validate two soil-vegetation-atmosphere-transfer (SVAT) schemes: TERRA-ML and the Community Land Model (CLM). Both SVAT schemes are run in standalone mode (decoupled from an atmospheric model) and forced with meteorological in-situ measurements obtained at several tropical African sites. Model performance is quantified by comparing simulated sensible and latent heat fluxes with eddy-covariance measurements. Our analysis indicates that the Community Land Model corresponds more closely to the micrometeorological observations, reflecting the advantages of the higher model complexity and physical realism. Deficiencies in TERRA-ML are addressed and its performance is improved: (1) adjusting input data (root depth) to region-specific values (tropical evergreen forest) resolves dry-season underestimation of evapotranspiration; (2) adjusting the leaf area index and albedo (depending on hard-coded model constants) resolves overestimations of both latent and sensible heat fluxes; and (3) an unrealistic flux partitioning caused by overestimated superficial water contents is reduced by adjusting the hydraulic conductivity parameterization. CLM is by default more versatile in its global application on different vegetation types and climates. On the other hand, with its lower degree of complexity, TERRA-ML is much less computationally demanding, which leads to faster calculation times in a coupled climate simulation.

Citation: Akkermans, T., et al. (2012), Validation and comparison of two soil-vegetation-atmosphere transfer models for tropical Africa, J. Geophys. Res., 117, G02013, doi:10.1029/2011JG001802.

\section{Introduction}

[2] The lower boundary to the atmosphere for fluxes of radiation, heat, water, momentum and chemical compounds

\footnotetext{
${ }^{1}$ Department of Earth and Environmental Sciences, Katholieke Universiteit Leuven, Heverlee, Belgium.

${ }^{2}$ Now at Vlaamse Instelling voor Technologisch Onderzoek (VITO), Mol, Belgium.

${ }^{3}$ Meteorologisches Observatorium Lindenberg, Deutscher Wetterdienst, Tauche, Germany.

${ }^{4}$ Ecologie Fonctionnelle et Biogéochimie des Sols and Agro-écosystèmes, Centre de Coopération Internationale en Recherche Agronomique pour le Développement (CIRAD), Montpellier, France.

${ }^{5}$ Centre de Recherche sur la Durabilité et la Productivité des Plantations Industrielles (CRDPI), Pointe-Noire, Republic of the Congo.

${ }^{6}$ Departamento de Ciências Atmosféricas, Escola Superior de Agricultura Luiz de Queiroz, Universidade de São Paulo, São Paulo, Brazil.

${ }^{7}$ Department of Physical Geography and Ecosystem Science, Lund University, Lund, Sweden.

${ }^{8}$ Grassland Science Group, Institute for Agricultural Sciences (IAS), ETH Zurich, Zurich, Switzerland.

${ }^{9}$ Institut für Agrarrelevante Klimaforschung, Johann Heinrich von Thünen Institut, Braunschweig, Germany.

Copyright 2012 by the American Geophysical Union. 0148-0227/12/2011JG001802
}

is provided by the land surface [Stöckli et al., 2008]. The importance of these fluxes for the climate system has already been demonstrated in several studies (e.g., Pielke [2005]; Seneviratne et al. [2006]; Pitman [2003]). Land-atmosphere interactions in tropical Africa are very dynamic, e.g., tropical forests have a large impact on surface temperature by physiological processes (through latent heat flux) rather than by radiative processes (through albedo), which is completely different from midlatitude or boreal regions [Snyder et al., 2004], making this region an essential study area.

[3] Soil-vegetation-atmosphere transfer (SVAT) schemes, also known as land-surface parameterizations (LSP) or landsurface schemes (LSS), simulate surface characteristics, e.g., properties of soil, vegetation and lakes, and calculate the matching turbulent fluxes as lower atmospheric boundary conditions in global or regional atmospheric models (for both numerical weather prediction and climate applications). During the last decades SVAT schemes have been developed from simple energy balance parameterizations to complex sub-models including a full integration of connected biogeochemical processes [Sellers et al., 1997]. Intercomparison studies were done in order to objectively quantify and compare the performance of different SVAT schemes, most notably by the PILPS (Project for the Intercomparison of 
Land-Surface Parameterization Schemes) comparing 23 schemes of different complexity [Henderson-Sellers et al., 1996]. The study revealed a considerable spread among simulated water and heat fluxes and a significant parameterization uncertainty [Pitman and Henderson-Sellers, 1998]. Similar results were found in subsequent intercomparison studies [Dirmeyer et al., 1999; Boone et al., 2004]. Although not yet entirely understood, for many SVAT parameterizations the uncertainty originates from the fact that simulated processes are based on few field observations and idealized experiments [Stöckli et al., 2008]. Therefore including regions with sparse observations is a fundamental objective.

[4] Model validation and improvement partly consists of tuning parameters in such a way that simulated values fit the measurements as good as possible. The majority of the flux measurements used for parameter tuning are located within the extra-tropical Northern Hemisphere [Williams et al., 2009], particulary forest ecosystems, hence model validation and improvement is biased toward these observations. Therefore, also including flux observations outside temperate and boreal climate zones should be an important priority.

[5] To target the above mentioned resarch objectives (i.e., including sparsely covered and tropical regions), this study uses flux observations from four sites in sub-Saharan Africa, which have not yet been used for an extensive validation of a SVAT schemes' energy balance; instead the data is mainly used for carbon balance studies [e.g., in Ardö et al., 2008; Bombelli et al., 2009; Merbold et al., 2009; Sjöström et al., 2011]. Previous SVAT scheme validation studies for Africa concentrated on West Africa in the context of GLOWAVolta, AMMA and HAPEX campaigns [e.g., Schüttemeyer et al., 2008; Saux-Picart et al., 2009; Lauwaet et al., 2008].

[6] The focus of this study will be on the performance of two state-of-the-art schemes which differ in their degree of complexity: TERRA-ML, version 4.0, developed at the German Weather Service (DWD); and the Community Land Model (CLM), version 3.5, developed at the National Center of Atmospheric Research (NCAR). TERRA-ML (also called "TERRA" in figures and tables) and CLM3.5 are originally designed as components of the atmospheric models maintained respectively by DWD and NCAR. It is possible, however, to use the schemes apart from their native atmospheric host model and to couple them to another atmospheric model (e.g., Davin et al. [2011] describes the coupling of CLM3.5 to the atmospheric model of DWD), allowing a choice of SVAT scheme based on an objective intercomparison independently from the choice and performance of the atmospheric model.

[7] Following the methodology applied in the second phase of PILPS [Pitman and Henderson-Sellers, 1998], both SVAT schemes are run in standalone mode by decoupling them from the atmospheric model and forcing the atmospheric boundary conditions with meteorological in-situ measurements. Therefore the schemes can be regarded as individually functioning models and their performance can be evaluated independently from atmospheric models. The SVAT models are run with a $1 \mathrm{D}$ vertical column grid without a spatial dimension (single grid cell approach). This approach is useful to assess model biases which originate from the SVAT component, and to isolate them from general biases of the atmospheric host model.

\section{Method and Data}

\subsection{Model Description}

[8] Each soil layer in both models has a water budget depending on extraction by evapotranspiration, runoff, capillary and gravitational transports, and vertical boundaries (e.g., from adjacent soil layers). Forced by climatic conditions and based on a range of mechanistic equations for hydrological (soil) and biophysical (vegetation) processes, the models simulate fluxes of radiation, water and heat. Specific model properties and characteristics are discussed in Sections 2.1.1 and 2.1.2.

\subsubsection{Community Land Model (CLM)}

[9] CLM is the SVAT component of the global climate model CCSM (Community Climate System Model) Version 3 [Collins et al., 2006]. All vegetation characteristics are prescribed separately for seventeen so-called "Plant Functional Types" or PFT's [Bonan et al., 2002]. These are basic vegetation types which can be combined to represent more complex biomes, e.g., a savannah biome can be composed by combining grassland with deciduous tropical trees. One single grid cell can contain up to four different PFT's for which energy and moisture fluxes are simulated. The grid cell averaged flux is calculated according to the PFT's areal proportions (tile-approach). Vegetation parameters are mainly defined in an extensive set of PFT-dependent constants (e.g., optical and aerodynamic parameters, root distribution parameters, photosynthetic capacities..) listed in Oleson et al. [2004], complemented with spatially-varying data sets for leaf area index (LAI), stem area index (SAI) and canopy height. Soil albedo $\left(\alpha_{\text {soil }}\right)$ depends on spatially-varying soil color, and plant albedo $\left(\alpha_{\text {plant }}\right)$ depends on PFT-dependent optical properties (e.g., leaf albedo, stem albedo). The total surface albedo is a combination of both, depending on the proportion of sunlit soil exposure through the canopy (which in turn depends on LAI and SAI), and is calculated for the near-IR and visible spectrum separately. The soil column has a total depth of $3.43 \mathrm{~m}$ and consists of ten layers, each of which can have a different soil texture (provided by a yet another spatially varying data set). Hydraulic conductivity and diffusivity are parameterized using formulations by Clapp and Hornberger [1978]. A prognostic aquifer scheme allows a variable groundwater table to rise into the soil column or fall below it [Niu et al., 2007]. A detailed model description of CLM3.0 is given by Oleson et al. [2004]. For modifications in CLM3.5, see Oleson et al. [2007]. On the basis of recommendations from the model developers, an optimal model time step of 1200 seconds was chosen.

\subsubsection{TERRA-ML}

[10] TERRA-ML is the SVAT component of the regional atmospheric model COSMO (Consortium for Small-scale Modeling), mainly used as an operational forecast model by the German Weather Service (COSMO-EU and COSMODE; see Baldauf et al. [2011]) and more recently applied on climate scales (COSMO-CLM; see Rockel et al. [2008]). It is also part of the operational global atmospherical model GME from the German Weather Service [Majewski et al., 2002]. The vegetation within each grid cell is characterized 
Table 1. Flux Towers Used in This Study

\begin{tabular}{|c|c|c|c|c|c|c|c|c|c|c|}
\hline Site & $\begin{array}{l}\text { Longitude } \\
\left({ }^{\circ} \mathrm{E}\right)\end{array}$ & $\begin{array}{l}\text { Latitude } \\
\left({ }^{\circ} \mathrm{N}\right)\end{array}$ & Country & $\begin{array}{r}\operatorname{Elev}^{a} \\
(\mathrm{~m})\end{array}$ & $\begin{array}{l}\text { Ref } \\
(\mathrm{m})\end{array}$ & $\begin{array}{l}\text { Period of Study } \\
\quad(\mathrm{yr} / \mathrm{mon})\end{array}$ & $\begin{array}{l}\mathrm{MAT} \\
\left({ }^{\circ} \mathrm{C}\right)\end{array}$ & $\begin{array}{l}\text { MAP } \\
(\mathrm{mm})\end{array}$ & Vegetation & Biome \\
\hline Kissoko & 11.98 & -4.79 & Republic of Congo & 108 & 23.25 & $2004 / 04-2006 / 03$ & 23.5 & 1076 & Eucalyptus trees & Evergreen forest \\
\hline Tchizalamou & 6 & -4.29 & Republic of Congo & 82 & 3.8 & $2006 / 0$ & 25.7 & 1150 & Grass & Grassland \\
\hline Demokeya & 30.48 & 13.28 & Sudan & 500 & 9 & 2007/10-2009/07 & 26 & 320 & Acacia trees + Grass & Sparse savannah \\
\hline Mongu & 23.25 & -15.44 & Zambia & 1053 & 19.5 & 2007/10-2008/11 & 24.6 & 945 & Miombo woodland & Deciduous woodland \\
\hline
\end{tabular}

${ }^{a} \mathrm{Elev}$ is the elevation of the flux tower above sea level; Ref is the height of the flux measurements above the surface; MAT and MAP are mean annual temperature and mean annual precipitation.

by a small number of parameters, being LAI, plant cover, root depth and roughness length. Based on the Global Land Cover 2000 data set (GLC2000), a number of vegetation types is defined for which all parameters have a specific value. No distinction is made between, e.g., tropical, temperate and boreal forests (note that TERRA-ML does not explicitly recognize vegetation types, but only uses the values of vegetation parameters). For LAI and plant cover, the look-up table [Doms et al., 2011] provides a minimum and maximum, from which the model derives an annual cycle: for the extra-tropical Northern Hemisphere, a growing and resting period is calculated according to latitude. This is shifted 180 days for the extra-tropical Southern Hemisphere. In the tropics $\left(20^{\circ} \mathrm{N}-20^{\circ} \mathrm{S}\right)$ all months are considered growing period (constant and maximum values of LAI and plant cover). Finally a height correction factor is applied (only on LAI). The (total) surface albedo within a grid cell is a combination of $\alpha_{\text {plant }}$ and $\alpha_{\text {soil }}$, weighted by the areal proportion of plant cover in the grid cell. $\alpha_{\text {soil }}$ and soil texture are depending on six spatially-varying soil types. Plant transpiration and soil evaporation are parameterized using the BATS scheme [Dickinson, 1984]. With only six hydrological layers, a vertically homogeneous soil texture and a total depth of $2.43 \mathrm{~m}$, the soil column is less sophisticated than in CLM. Parameterization of hydraulic conductivity and diffusivity is based on Rijtema [1969]. The lower boundary condition (at lowest soil level) consists of free drainage from gravitational water, only allowing a downward water flux. The full model documentation can be found in Doms et al. [2011]. In a sensitivity test, a range of model time steps was applied. Time steps smaller than 360 seconds did not influence the results significantly, hence this was chosen as an optimal trade-off between performance and computing time.

[11] When TERRA-ML is used in a coupled climate model, its computational cost is lower than CLM. The wall time needed for a simulation of one year depends on machine type, number of processors, etc. and hence can not easily be presented quantitatively. To give a indicative comparison, the walltime at the K.U.Leuven supercomputer for one year on 32 Nehalem X5560 processors amounts 39.6 hours when coupled to TERRA-ML, and 55 hours when coupled to CLM, which is a difference of about $40 \%$.

\subsection{Model Setup}

\subsubsection{Initial Conditions}

[12] The models are set up with the same initial conditions for soil moisture (full saturation) and soil temperature $(300 \mathrm{~K})$. The spin-up time is defined as the time needed to reach equilibrium of soil water levels, which is achieved after repeatedly re-initializing the model from the former model output. All analyses are done on spun-up model runs. 2.2.2. Vegetation Composition

[13] The last columns of Table 1 give an overview of the general vegetation characteristics around the flux tower sites used in this study. The vegetation can generally be characterized as a specific GLC2000 vegetation class in TERRAML (Table 2) or a combination of PFT's in CLM (Table 3). The only flux site which has a heterogeneous PFT composition is Demokeya, for which the savannah vegetation is simulated by $80 \%$ grassland (GRA) and $20 \%$ tropical deciduous trees (BDT). In TERRA-ML, the flux site is

Table 2. Overview of Input Parameters in TERRA-ML

\begin{tabular}{|c|c|c|c|c|c|}
\hline & Location & Kissoko & Tchizalamou & Demokeya & Mongu \\
\hline & GLC2000 Class & $\begin{array}{c}\text { Evergreen } \\
\text { Broadleaf Forest }\end{array}$ & $\begin{array}{l}\text { Herbaceous } \\
\text { Vegetation }\end{array}$ & $\begin{array}{l}\text { Deciduous } \\
\text { Shrubs }\end{array}$ & $\begin{array}{c}\text { Deciduous Closed } \\
\text { Broadleaf Forest }\end{array}$ \\
\hline \multirow[t]{8}{*}{ Default values } & Plant cover $(\mathrm{PC})$ & 0.8 & 0.9 & 0.8 & 0.8 \\
\hline & Roughness length $\left(\mathrm{z}_{0}\right)$ & $1.0 \mathrm{~m}$ & $0.03 \mathrm{~m}$ & $0.15 \mathrm{~m}$ & $1.0 \mathrm{~m}$ \\
\hline & Max. leaf area index (LAI) & 2.4 & 3.1 & 2.0 & 3.4 \\
\hline & Leaf area index (LAI) & 2.4 & 3.1 & 1.9 & 2.3 \\
\hline & Root depth (RD) & $1.0 \mathrm{~m}$ & $0.6 \mathrm{~m}$ & $2.0 \mathrm{~m}$ & $1.0 \mathrm{~m}$ \\
\hline & Soil type & sand & sand & sand & sand \\
\hline & Soil albedo $\left(\alpha_{\text {soil }}\right)$ & 0.30 & 0.30 & 0.30 & 0.30 \\
\hline & Plant albedo $\left(\alpha_{\text {soil }}\right)$ & 0.15 & 0.15 & 0.15 & 0.15 \\
\hline \multirow[t]{4}{*}{ Modified values } & Leaf area index (LAI) ${ }^{\mathrm{a}}$ & $1.6-1.9$ & $0.3-0.8$ & $0.1-1.4$ & $1.0-2.3$ \\
\hline & Root depth (RD) & $3.4 \mathrm{~m}$ & - & - & $2.3 \mathrm{~m}$ \\
\hline & Soil albedo $\left(\alpha_{\text {soil }}\right)$ & - & 0.35 & 0.35 & - \\
\hline & Plant albedo $\left(\alpha_{\text {soil }}\right)$ & 0.20 & 0.25 & 0.25 & - \\
\hline
\end{tabular}

${ }^{\mathrm{a}}$ Values are minimum and maximum LAI of the annual cycle in Figure 2. 
Table 3. Overview of Default Input Parameters in CLM

\begin{tabular}{ccccc}
\hline Location & Kissoko & Tchizalamou & Demokeya $^{\mathrm{a}}$ & Mongu \\
\hline PFT combination & $100 \% \mathrm{BET}^{\mathrm{b}}$ & $100 \%$ GRA & $\begin{array}{c}80 \% \mathrm{GRA} \\
20 \% \mathrm{BDT}\end{array}$ & $100 \% \mathrm{BDT}$ \\
\hline $\begin{array}{c}\text { Leaf area index } \\
\text { (LAI) }\end{array}$ & $1.6-1.9$ & $0.1-1.4$ & $0.3-0.8$ & $1.0-2.3$ \\
$\begin{array}{c}\text { Stem area index } \\
\text { (SAI) }\end{array}$ & $0.3-0.4$ & $0.4-0.8$ & $0.2-0.4$ & $0.5-0.7$ \\
$\begin{array}{l}\text { Canopy height } \\
\text { Canopy bottom }\end{array}$ & $35.0 \mathrm{~m}$ & $0.5 \mathrm{~m}$ & $4.0 \mathrm{~m}$ & $18.0 \mathrm{~m}$ \\
\hline
\end{tabular}

${ }^{\mathrm{a}}$ All values are averages for the 2 PFTs.

${ }^{\mathrm{b}} \mathrm{BET}$ is broadleaved evergreen tropical tree, GRA is grassland, and BDT is broadleaved deciduous tropical tree.

${ }^{c}$ Values are minimum and maximum LAI of the annual cycle in Figure 2.

categorized as "deciduous shrubs" as well as "deciduous open broadleaved forest", however both classes have the same parameter values.

\subsubsection{Default Input Parameters}

[14] For the main model comparison and validation (Section 3), input parameters (e.g., $\alpha_{\text {soil }}$ in TERRA-ML) are not tuned to site-specific observations since the ultimate objective of a SVAT model is the coupling to a spatially explicit atmospheric model, without modifying these parameters on point-based scale. An overview and comparison of the default input parameters can be found in Table 3 (CLM) and 2 (TERRA-ML).

[15] In CLM, the default input data set for LAI and SAI is a spatially-varying annual cycle, based on MODIS satellite images [Lawrence and Chase, 2007]. For every grid cell a further distinction is made between different vegetation types. Hence the values depend on the spatial coordinates of the flux site, the time of the year and the vegetation type ("PFT" in CLM). The annual course of LAI at the different flux sites is given in Figure 2. The MODIS LAI at Demokeya is discussed in Ardö et al. [2008] and for Mongu see Huemmrich et al. [2005]. The model allows a spatiallyvarying canopy height and bottom, but for the moment these are still set to PFT-dependent constants. The default input data set for soil color is also based on MODIS data [Lawrence and Chase, 2007]. Layer-dependent sand and clay percentages are prescribed from the global soil profile texture data sets of Reynolds et al. [2000], and are currently the default soil texture inputs for CLM.

[16] In TERRA-ML, default LAI and plant cover in the tropics are constants, only affected by a height correction factor. For most of the flux tower sites, the calculated LAI approximates the maximum value from the look-up tables [Doms et al., 2011], only for the Mongu site $(>1000 \mathrm{~m})$ the LAI decreased drastically due to the height correction (from 3.4 to 2.3). TERRA-ML has six soil classes (sand, sandy loam, loam, clay loam, clay and peat) based on the FAO/ UNESCO Soil Map of the World. Based on the description of local soil characteristics by the flux tower managers, all sites are best represented by the "sand" class, containing $90 \%$ sand and $5 \%$ clay, (the "sandy loam" class would imply a texture of only $65 \%$ sand). The "sand" class has a soil albedo of 0.30 (Table 2). Total surface albedo is calculated as follows:

$$
\alpha=\left(\alpha_{\text {plant }} \cdot P C\right)+\left(\alpha_{\text {soil }} \cdot(1-P C)\right)
$$

in which $\alpha_{\text {plant }}$ equals 0.15 (non-spatially hard-coded constant) and PC is plant cover (0.8 to 0.9 at all flux sites).

\subsubsection{Meteorological Forcing Data}

[17] The models are forced with hourly meteorological input data at reference height (Table 1). They both require continuous time series of precipitation rate $\left(P ; \mathrm{mm} \mathrm{s}^{-2}\right)$, air temperature $\left(T_{a} ; \mathrm{K}\right)$, relative humidity $(R H ; \%)$, wind speed $\left(u ; \mathrm{m} \mathrm{s}^{-2}\right)$, downward short-wave radiation $\left(S W_{d} ; \mathrm{W} \mathrm{\textrm {m } ^ { - 2 } )}\right.$ and downward long-wave radiation $\left(L W_{d} ; \mathrm{W} \mathrm{m}^{-2}\right)$. In addition CLM also needs surface pressure $\left(P_{s} ; \mathrm{Pa}\right)$ which is a constant in TERRA-ML and calculated as the overall mean surface pressure adjusted for each site. Analogous to Stöckli and Vidale [2005], data gaps (e.g., due to measurement failure) or inconsistencies (e.g., negative solar irradiance) are bypassed using a linear interpolation, except for $P$ which is substituted with zeros, and $S W_{d}$ which is estimated by interpolating only between similar local solar times. This is done in order to provide a required continuity in the input data. Only small gaps are allowed ( $<1$ day) since long interruptions could affect the simulation. Model output corresponding with gap-filled or substituted meteorological data is not taken into account for the evaluation.

[18] $L W_{d}$ is only observed at the Mongu flux site and has to be estimated for the other flux sites. This is typically done by a semi-empirical model based on temperature and vapour pressure. These models are calibrated with a collection of weather station data, and hence are limited in their geographical applicability. Because of the scarce data availability in the tropics, Aguiar et al. [2011] applied and evaluated seven models in the Amazon region for a forest and pasture site: the Idso model [Idso, 1981] performed the best in humid conditions but overestimated $L W_{d}$ during dry conditions, while the Brutsaert model [Brutsaert, 1975] was better fit for dry conditions since it yields generally lower values. In this study, the two models are compared with observed $L W_{d}$ for the Mongu site. Given the pronounced seasonality at Mongu, it is a good reference for both humid and dry conditions. The results are shown in Figure 3 and confirm the findings of Aguiar et al. [2011]. Consequently the Idso model will be used for the two wet-equatorial flux sites (Kissoko and Tchizalamou) and the Brutsaert model for the semi-arid flux site (Demokeya). For Mongu the observed quantities are used. $L W_{d}$ is estimated as

$$
L W_{d}=\epsilon_{o} \sigma T_{a}^{4}
$$

where $\epsilon_{o}$ is the atmospheric emissivity and depends on the chosen model. The parameterization of Idso and Brutsaert are respectively

$$
\begin{gathered}
\epsilon_{o}=0.7+5.95 \cdot 10^{-5} \cdot e_{a} \cdot e^{\frac{1500}{T_{a}}} \\
\epsilon_{o}=1.24 \cdot\left(\frac{e_{a}}{T_{a}}\right)^{\frac{1}{7}}
\end{gathered}
$$

where $e_{a}(\mathrm{~Pa})$ is the atmospheric vapour pressure. In case $P_{s}$ is not measured, it is estimated by

$$
P_{s}=e^{-\frac{M g z}{R T_{a}}} P_{s o}
$$

where $M$ is the molecular weight of air, $g$ the gravitational acceleration, $z$ the measurement height above sea level 

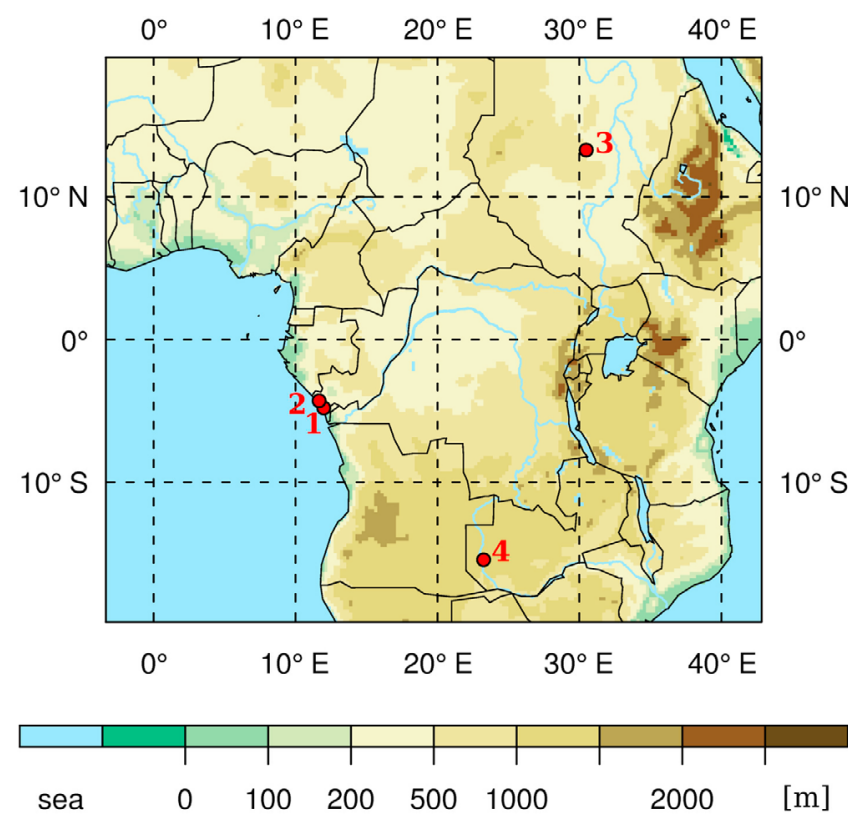

Figure 1. Locations of the four flux sites, indicated by red dots. (1) Kissoko, (2) Tchizalamou, (3) Demokeya, (4) Mongu.

(Table 1), R the universal gas constant, and $P_{s o}$ the mean sea level pressure $(1013 \mathrm{hPa})$.

\subsection{Evaluation Data}

[19] Figure 1 and Table 1 give an overview of the flux tower sites used in this study with their respective coordinates and general characteristics. These sites are either associated with or part of the CarboAfrica network [Bombelli et al., 2009] which is a part of the global FLUXNET network [Baldocchi, 2001], providing a comprehensive data set of measured micrometeorology, i.e., surface energy, water and carbon fluxes, together with general meteorological observations. The Kissoko (forest) and Tchizalamou (grass) sites are representative for a near-equatorial $\left(4^{\circ} \mathrm{S}\right)$ moist climate and are discussed in-depth by Nouvellon [2010] and Castaldi

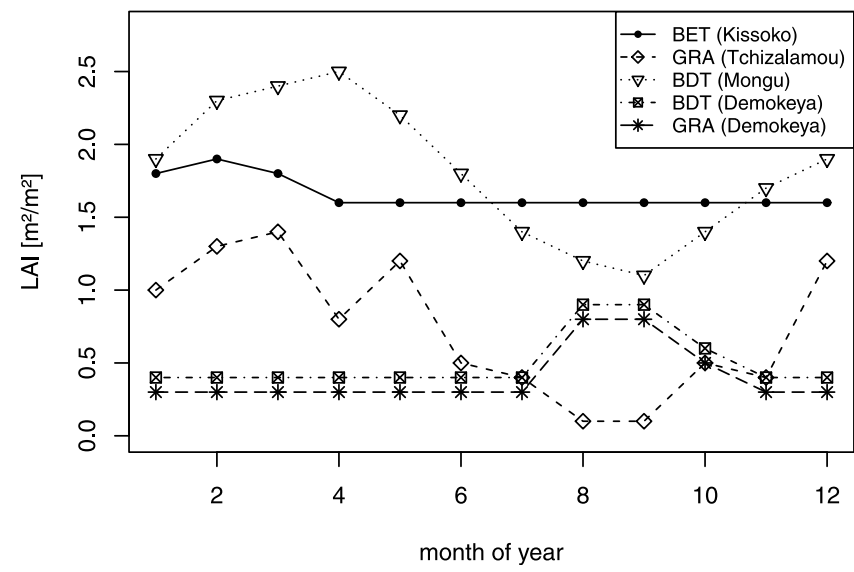

Figure 2. Monthly leaf area index (LAI) of different vegetation types at different flux sites, based on Lawrence and Chase [2007]. BET is broadleaved evergreen tropical tree, BDT is broadleaved deciduous tropical tree and GRA is grassland.

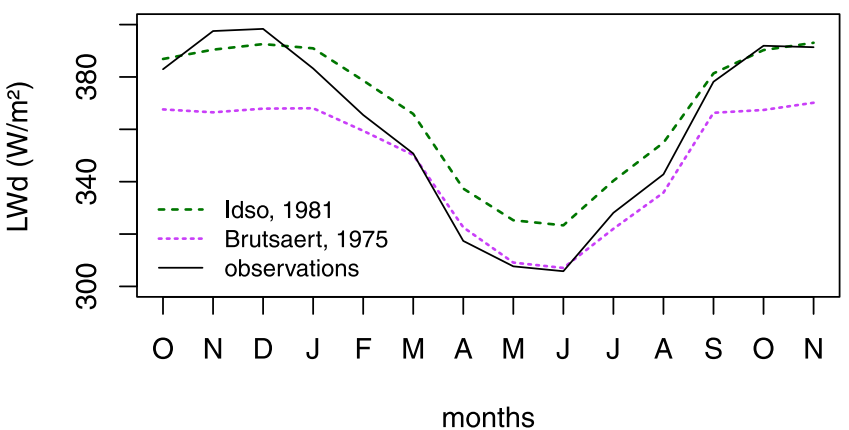

Figure 3. Observed and estimated monthly incoming longwave radiation at the Mongu site, 2007-2009.

et al. [2010]. Two other sites have a more pronounced seasonal climate resulting in a deciduous woodland vegetation at the Mongu site $\left(15^{\circ} \mathrm{S}\right)$ and a savannah vegetation at the Demokeya site $\left(13^{\circ} \mathrm{N}\right)$, discussed in Merbold et al. [2010] and Ardö et al. [2008].

[20] Half-hourly surface sensible $\left(\mathrm{H} ; \mathrm{W} \mathrm{m}^{-2}\right)$ and latent (LE; $\mathrm{W} \mathrm{m}^{-2}$ ) heat fluxes were measured with the eddy covariance technique, documented by Moncrieff et al. [1997]. None of the validation data were gap-filled and hence corresponding points in time are not taken into account for the model evaluation.

[21] Based on findings of Sellers et al. [1990] and Crago and Brutsaert [1996], random measurement uncertainty $\left(U_{L E}\right.$ and $\left.U_{H} ; \mathrm{W} \mathrm{m}^{-2}\right)$ is introduced on LE and $\mathrm{H}$ observations during each time step. The uncertainties consist of a relative error constrained by a minimum error for smaller flux magnitudes:

$$
\begin{aligned}
U_{L E} & =\max (0.15 \cdot L E, 20) . \\
U_{H} & =\max (0.15 \cdot H, 20) .
\end{aligned}
$$

[22] Net radiation $\left(R n ; \mathrm{W} \mathrm{m}^{-2}\right)$ was measured with a single-output radiometer (not indicating separate energy balance components), independently from the measurements of $S W_{d}$. Because no useful ground heat flux observations are available for most of the flux sites, the ground heat flux is parameterized as a funcation of LAI and $R n$, according to Choudhury et al. [1987] and adapted by Kustas et al. [1993]:

$$
G=R n \cdot 0.34 \cdot \exp (-0.46 \cdot L A I) .
$$

[23] Results are presented as monthly averages which could not be calculated for months without flux measurements, explaining the occasional gaps in the graphs. Modelderived monthly averages are calculated by omitting data which corresponds to gaps and inconsistencies in meteorological forcing data (Section 2.2.4) and gaps in micrometeorological flux data (LE and $\mathrm{H}$ ).

[24] Average energy fluxes are only calculated for daytime, defined as all data corresponding with a measured $R n>$ $50 \mathrm{~W} \mathrm{~m}^{-2}$ [Nussbaum et al., 1995; Leeuw and Zantvoort, 1997]. This is done in order to prevent a flattening-out of the signal caused by the much lower nighttime fluxes.

[25] Data gaps could occur on preferential times of the daily cycle (e.g., at noon) and hence bias the monthly flux 


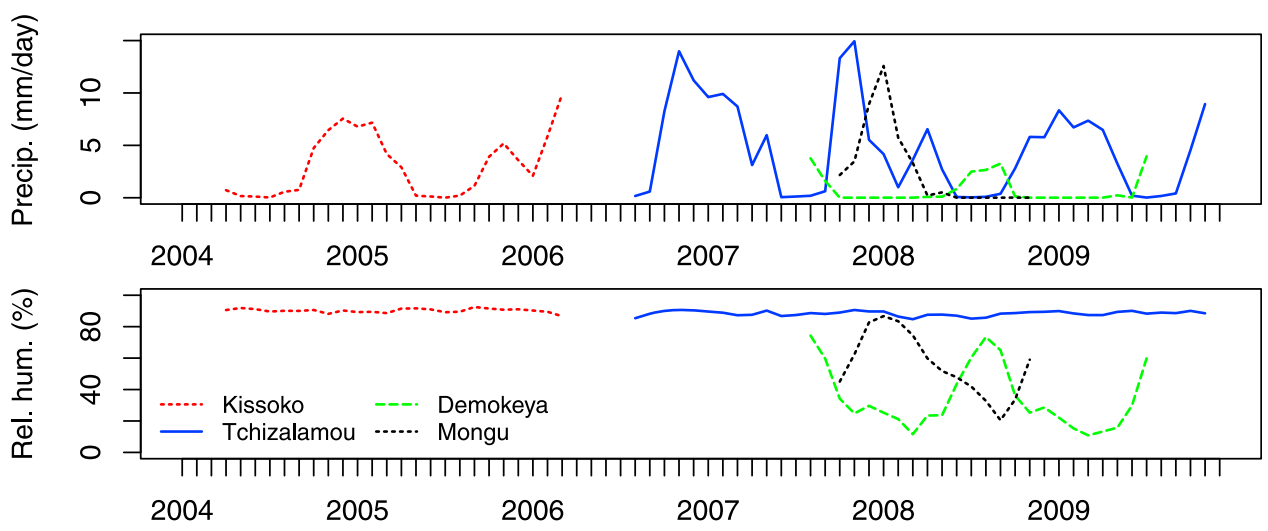

Figure 4. Observed monthly averaged (top) precipitation and (bottom) humidity.

averages. Therefore first the monthly means of all valid flux data are calculated per hourly time segment of the daily cycle (ignoring possible data gaps), from which a weighted average is calculated according the frequency of $R n>50 \mathrm{~W}$ $\mathrm{m}^{-2}$ in each segment.

[26] Uncertainty ranges are indicated by error bars and calculated as monthly means of the half-hourly uncertainties, however the real errors are likely to be lower since propagated uncertainty decreases with accumulation time [Williams et al., 2009].

\section{Model Comparison and Validation Using Default Input Parameters}

\subsection{Monthly Timescale}

[27] The Kissoko site is characterized by a long wet season spanning from October to April (Figure 4). A minimum observed latent heat flux $\left(100 \mathrm{~W} \mathrm{~m}^{-2}\right)$ is maintained yearround due to the transpiration capacity of the vegetation
(Figure 5a). Consequently the annual cycle has a relatively small amplitude. Both models overestimate LE during the wet season with around $50-70 \mathrm{~W} \mathrm{~m}^{-2}$ in 2005 and around $25 \mathrm{~W} \mathrm{~m}^{-2}$ in 2006. In contrast to CLM, TERRA-ML generally fails to capture a sustained evapotranspiration during the dry season, and hence underestimates LE (by about 50 $75 \mathrm{~W} \mathrm{~m}^{-2}$ ). Underestimations of latent heat flux correspond with overestimations of sensible heat flux, and vice versa (Figure 5b). The ground heat flux is generally well represented in both models (Figure 5c).

[28] Humidity and precipitation seasonality at the Tchizalamou site is similar to Kissoko's, and average monthly rainfall during wet seasons is much higher (Figure 4). Nevertheless, the grass vegetation limits observed LE (Figure 6a): the lower canopy cover captures less water to evaporate and allows more water to infiltrate the soil, and the photosynthetic active biomass is much lower, hence the transpiration rates too. The absence of deep roots explains the dry-season depressions, with an average value of $50 \mathrm{~W}$

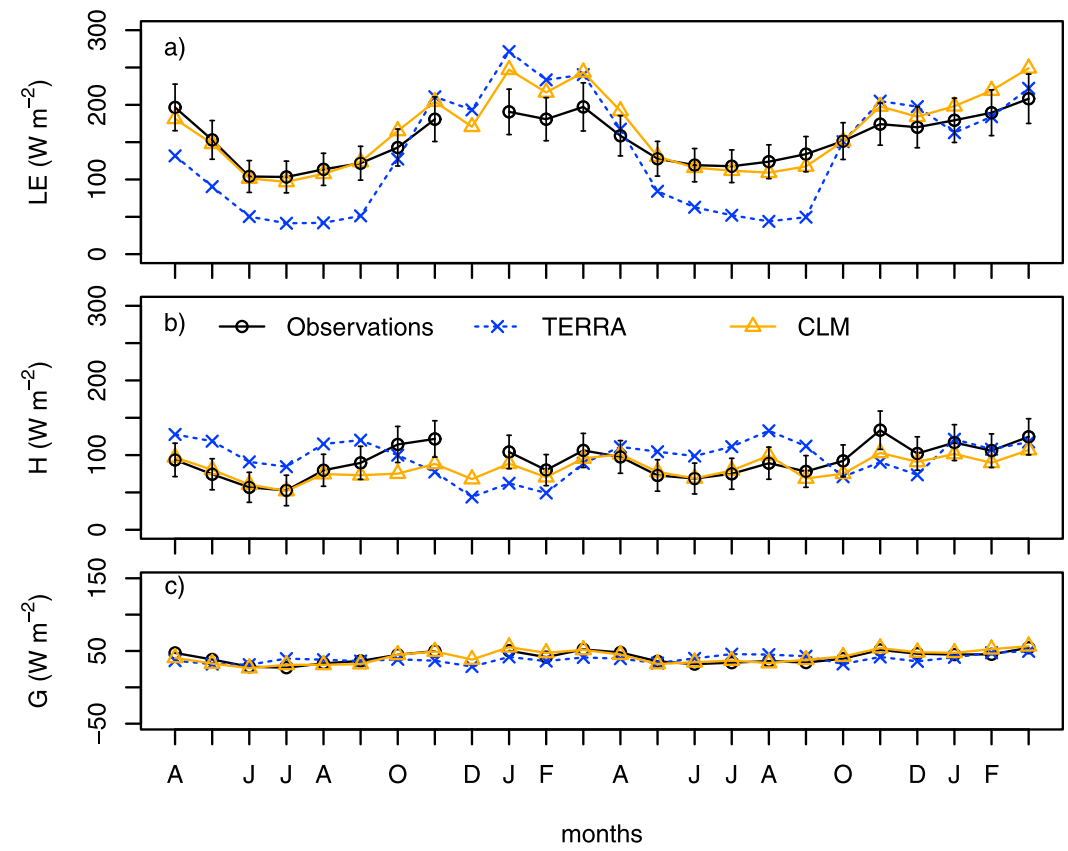

Figure 5. Monthly averaged energy fluxes (daytime) at the Kissoko site, 2004-2006: (a) LE; (b) H; (c) G. 

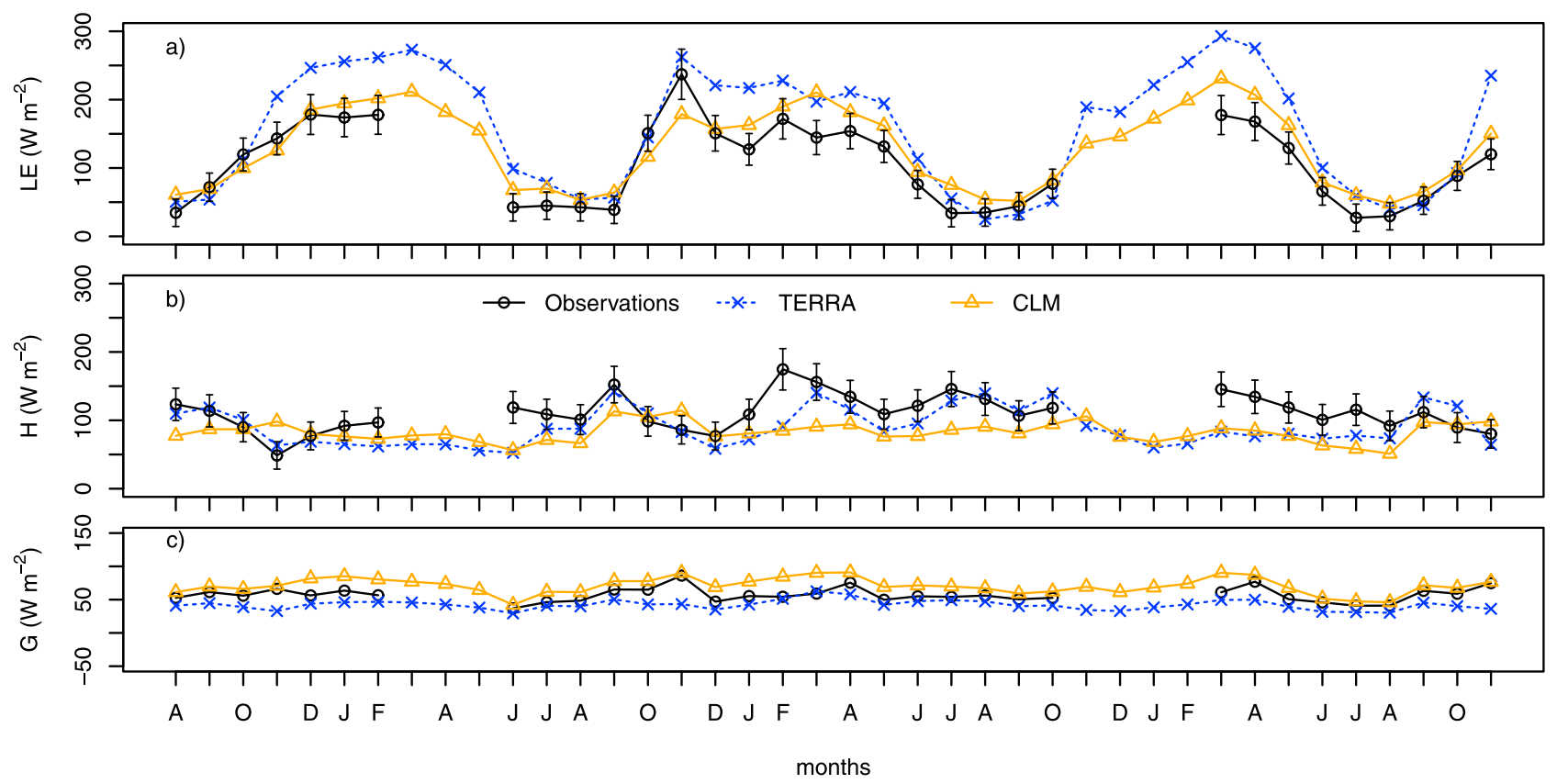

Figure 6. Monthly averaged energy fluxes (daytime) at the Tchizalamou site, 2006-2009: (a) LE; (b) H; (c) G.

$\mathrm{m}^{-2}$. LE is overestimated in the wet season with big differences between the models: TERRA-ML overestimates by up to $100 \mathrm{~W} \mathrm{~m}^{-2}$, while in CLM this is maximally $50 \mathrm{~W} \mathrm{~m}^{-2}$. The inter-model difference for LE is reflected by the other fluxes (Figures 6b and 6c), e.g., during the first wet season (2006-2007) the higher LE in TERRA-ML corresponds with a lower $\mathrm{H}$ and a lower $\mathrm{G}$. In the dry seasons, both models simulate LE equally well, while $\mathrm{H}$ is mostly underestimated by CLM $\left(30-50 \mathrm{~W} \mathrm{~m}^{-2}\right)$. The ground heat flux is systematically overestimated by CLM and underestimated by TERRA-ML, both by up to $30 \mathrm{~W} \mathrm{~m}^{-2}$ (Figure $6 \mathrm{c}$ ).

[29] The Demokeya flux site has a climatology of a short wet season (July to October) followed by eight dry months (Figure 4). Demokeya is located more to the north and its semi-arid savannah climate has lower precipitation amounts compared to the evergreen flux sites located closer to the equator. Water scarcity during the long dry season forces a higher Bowen ratio (H/LE) with an observed average monthly $\mathrm{H}$ of about $200 \mathrm{~W} \mathrm{~m}^{-2}$ (Figure $7 \mathrm{~b}$ ). LE is quasiconstant and very low (Figure $7 \mathrm{a}$ ). In the short wet season, the precipitation causes LE to peak, while $\mathrm{H}$ has exactly the opposite annual cycle. The overall performance of CLM is good, with underestimations of LE during the wet season (about $30 \mathrm{~W} \mathrm{~m}^{-2}$ ) and corresponding overestimations of H. In TERRA-ML this bias is even higher $\left(70 \mathrm{~W} \mathrm{~m}^{-2}\right)$, and also visible in the dry season $\left(30 \mathrm{~W} \mathrm{~m}^{-2}\right)$. Furthermore a strong and consistent overestimation of $\mathrm{H}$ can be seen (about $70 \mathrm{~W} \mathrm{~m}^{-2}$ ), causing monthly averages of $\mathrm{H}$ up to $300 \mathrm{~W} \mathrm{~m}^{-2}$. Finally the ground heat flux has an overestimation during dry season (maximally $50 \mathrm{~W} \mathrm{~m}^{-2}$ ) which disappears in the wet season (Figure 7c).

[30] At the Mongu flux site, the rainy season consists of the months from November to March (Figure 4). Compared to the evergreen forest site (Kissoko) a stronger precipitation peak occurs in January but the entire period only lasts for five months, explaining the vegetation's deciduous nature.
During the wet season, the flux partitioning of TERRA-ML is unrealistic with an overestimation of LE and underestimation of $\mathrm{H}$, on average respectively 100 and $60 \mathrm{~W} \mathrm{~m}^{-2}$ (Figures $8 \mathrm{a}$ and $8 \mathrm{~b}$ ). This bias is probably related to overestimated soil moisture in the topsoil layers. The dry season on the other hand is characterized by a well-simulated $\mathrm{H}$ and an underestimation of LE of about $30-60 \mathrm{~W} \mathrm{~m}^{-2}$. CLM simulates LE and $\mathrm{H}$ well during the wet season. Similar to TERRA-ML but to lesser extent, CLM also underestimates LE during the dry season $\left(20 \mathrm{~W} \mathrm{~m}^{-2}\right)$, while $\mathrm{H}$ is overestimated drastically $\left(50-70 \mathrm{~W} \mathrm{~m}^{-2}\right)$.

\subsection{Hourly Timescale}

[31] The evaluation on monthly (daytime-only) timescale does not give all information about the model performance. It is also important that the SVAT schemes can simulate the daily cycle with a good amplitude and phase. This can be evaluated generally by correlating simulated and observed hourly time series. An overview of model performance statistics is given in Table 4, showing correlation coefficients (R) and root mean square errors (RMSE) between brackets. A visualization in Taylor diagrams [Taylor, 2001] is shown in Figure 9, summarizing a number of statistical parameters. Statistics are calculated for entire time series on hourly timescale and hence are not to be compared directly to the daytime-only monthly averages (Figures 5 to 8). Correlation between simulated and observed fluxes is high for all models, with coefficients mostly exceeding 0.85 . Inter-model performance differences are mostly in favor of CLM, except for $\mathrm{H}$ at Tchizalamou. For Kissoko, the lower performance of dry-season LE in TERRA-ML can be seen in the RMSE as well as in correlation ( 0.87 versus 0.96 for CLM).

[32] In this study version 3.5 of the Community Land Model was used. However, the latest version (CLM4) includes a number of parameterization improvements, possibly alleviating some deficiencies noted in this study. 

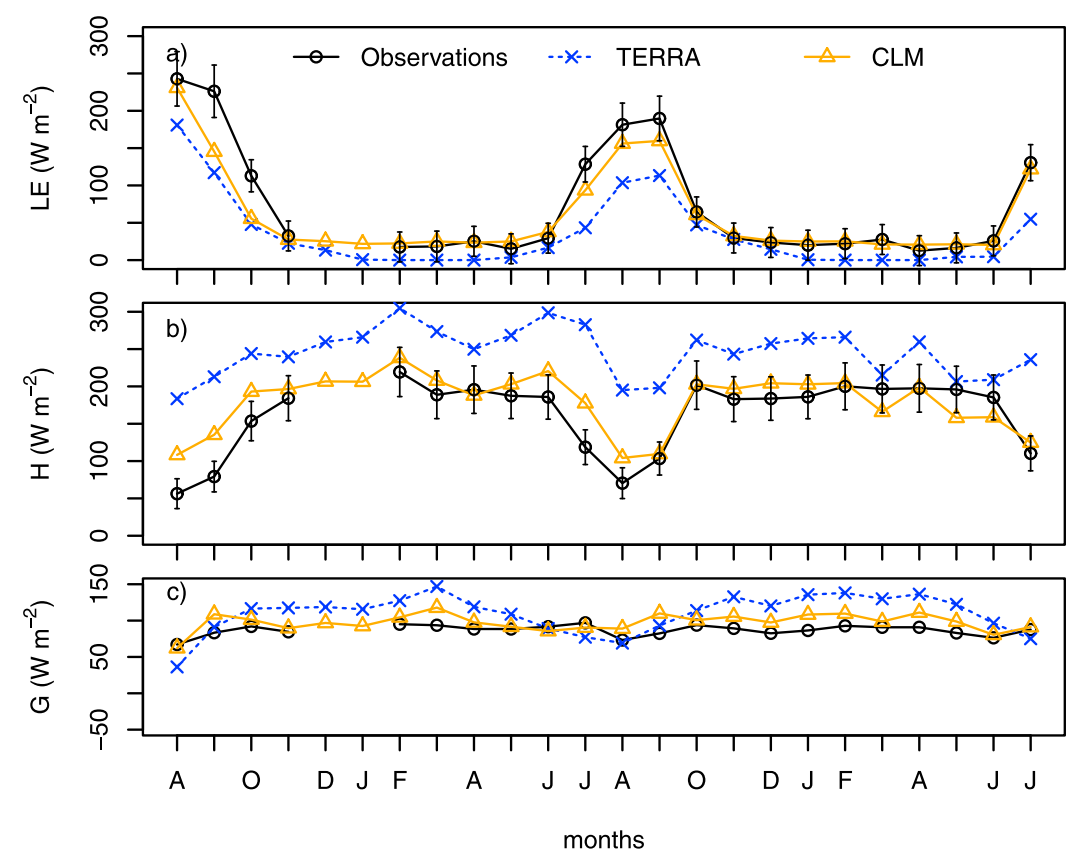

Figure 7. Monthly averaged energy fluxes (daytime) at the Demokeya site, 2007-2009: (a) LE; (b) H; (c) G.

A comparison of CLM3.5 and CLM4 is done by Lawrence et al. [2011] and indeed reveal improvements for the two tropical flux sites (Amazon region) with higher correlations and lower RMSEs in CLM4, especially for sensible heat flux.

[33] The major deficiencies noticed in TERRA-ML simulations are discussed in section 4 and addressed by modifications to input parameters. No important parameterizations

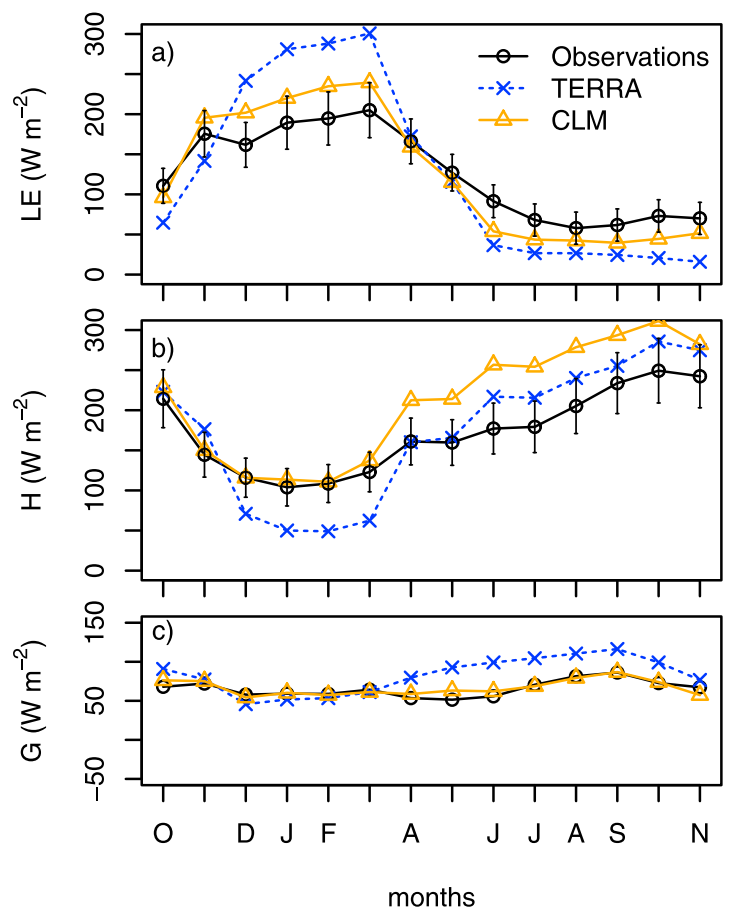

Figure 8. Monthly averaged energy fluxes (daytime) at the Mongu site, 2007-2009: (a) LE; (b) H; (c) G. or input parameters were modified since the model version used in this study.

\section{Modification of TERRA-ML}

\subsection{Modification of Input Parameters}

[34] Important issues in the default TERRA-ML simulations are the overestimation of LE, especially during the wet season (Figures 5a, 6a and 8a), the consistent overestimation of $\mathrm{H}$ at the Demokeya site (Figure 7b), and the failure to capture a sustained evapotranspiration during the dry season (Figure 5a and 8a).

[35] The main objective of this section is to enhance the performance of TERRA-ML and reveal the true capacities of the SVAT model after improving its input parameters. The modifications will be applied on all flux sites and the effect will be shown for all simulated fluxes (Figures 10-13). The default TERRA-ML simulation is represented by the broken blue lines.

\subsubsection{Leaf Area Index}

[36] The first parameter to modify in TERRA-ML is the LAI. A decrease of LAI might decrease overestimations of LE. Instead of the default constant value, a MODIS-based annual cycle of LAI is prescribed (Figure 2), which is the same as used by CLM and discussed in Section 2.1.2. The new LAI is based on spatially-varying satellite information and will therefore be more similar to observations than the default look-up table values. The new values are generally lower than the TERRA-ML defaults (Table 2), especially for the Tchizalamou site.

[37] The simulation with modified LAI is shown by green solid lines in Figures 10-13. For most of the flux sites, the LAI does not have a significant influence on any of the heat fluxes. Given its significant decrease in LAI, the simulated flux partitioning at Tchizalamou does show improvements: the overestimation of LE decreased with about $50 \mathrm{~W} \mathrm{~m}^{-2}$ 
Table 4. Model Performance Statistics for LE and H on Hourly Timescale (Correlation: RMSE) ${ }^{\mathrm{a}}$

\begin{tabular}{llccc}
\hline \multicolumn{1}{c}{ Site } & Flux & CLM & TERRA & TERRA $_{\text {mod }} \mathrm{b}$ \\
\hline Kissoko & LE & $\mathbf{0 . 9 6}(\mathbf{2 9 . 3 6})$ & $0.87(47.50)$ & $0.95(35.26)$ \\
& $\mathrm{H}$ & $\mathbf{0 . 9 3}(\mathbf{2 6 . 1 3})$ & $0.88(34.71)$ & $0.90(35.27)$ \\
Tchizalamou & LE & $0.90(\mathbf{3 7 . 3 4})$ & $\mathbf{0 . 9 2}(50.57)$ & $0.91(32.83)$ \\
& $\mathrm{H}$ & $0.90(33.80)$ & $\mathbf{0 . 9 2 ( 2 7 . 6 9 )}$ & $0.91(28.35)$ \\
Demokeya & LE & $\mathbf{0 . 8 9}(\mathbf{3 3 . 5 4})$ & $0.83(46.73)$ & $0.82(47.04)$ \\
& $\mathrm{H}$ & $\mathbf{0 . 9 6}(\mathbf{3 3 . 3 4})$ & $0.93(73.84)$ & $0.92(50.55)$ \\
Mongu & LE & $\mathbf{0 . 8 8}(\mathbf{4 2 . 9 4 )}$ & $0.86(54.88)$ & $0.87(56.64)$ \\
& $\mathrm{H}$ & $\mathbf{0 . 9 7}(46.74)$ & $0.95(\mathbf{4 2 . 0 7})$ & $0.94(43.44)$ \\
\hline
\end{tabular}

${ }^{\mathrm{a}}$ Bold numbers indicate best performance with default input parameters. Italics indicate significant improvements of TERRA with modified input parameters $\left(\right.$ TERRA $\left._{m o d}\right)$.

${ }^{\mathrm{b}}$ The hydraulic conductivity experiment for the Mongu site is not included since it is not applicable for all flux sites.

(Figure 11c) and the underestimation of $\mathrm{H}$ improved accordingly (Figure 11d).

\subsubsection{Surface Albedo}

[38] An increase of surface albedo decreases the available energy at the surface $(R n)$, and might alleviate overestimations of $\mathrm{H}$ and LE. The black solid lines in Figures 10a, 11a, 12a and 13a show the surface albedo observed by the SEVIRI radiometers onboard the METEOSAT-9 satellites [Schmetz et al., 2002; Schulz et al., 2009]. The data is available at CM-SAF (http://www.cmsaf.eu/) for the period may 2007 to present. For Kissoko, data of 2007-2009 is shown instead of 2004-2006. The grid cell resolution equals $15 \times 15 \mathrm{~km}$ which means that the values are not entirely representative for the immediate surroundings of the flux tower. However it is an indicative proxy and suitable for identifying serious model biases.

a)

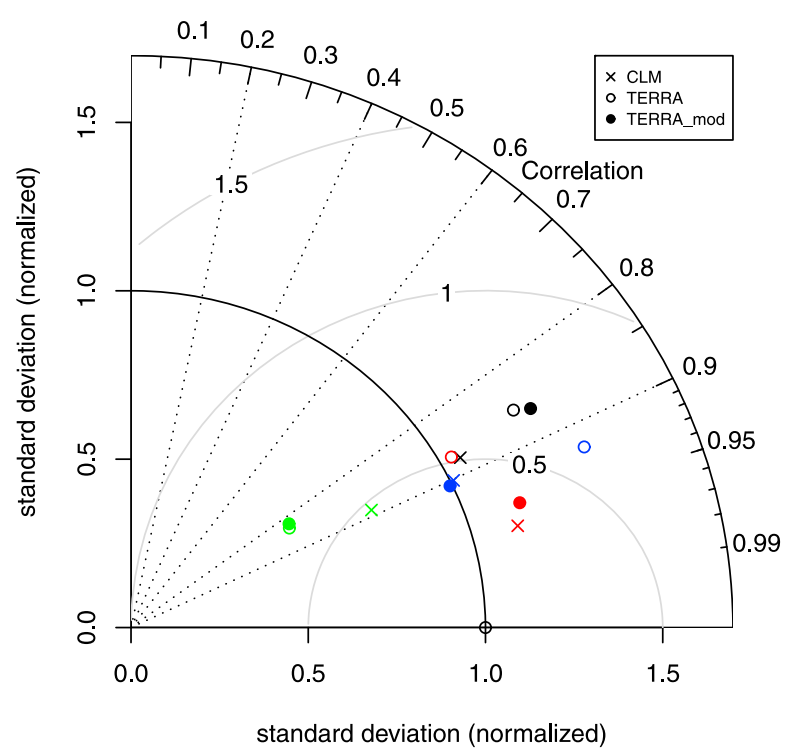

[39] In the case of Kissoko, Tchizalamou and Demokeya, TERRA-ML underestimates surface albedo (blue crosses in Figures 10a, 11a and 12a). To obtain a better match with the observations, $\alpha_{\text {soil }}$ and/or $\alpha_{\text {plant }}$ are increased for the three flux sites (Table 2). The new surface albedo is indicated by red crosses in the above mentioned figures. TERRA-ML allows the albedo to change according to plant cover (i.e., in an annual cycle), but since this is a constant value in the tropical region (Section 2.1.2), albedo is only slightly affected by superficial soil moisture variations.

[40] As a result of the albedo modification, $R n$ is simulated better at all three flux sites (10b, 11b and 12b). The graphs are showing the cumulative effect of consecutive modifications, hence contain the joint effect of modified LAI (Section 4.1.1) and modified albedo. Additional improvements might be obtained by taking into account a more detailed canopy structure (with, e.g., leaf inclination angle distribution) influencing light interception [Baldocchi et al., 2002], which is not included in the models used in this study. The propagation of the improvement to the heat fluxes is however different for every flux site. At Kissoko, the small decrease of overestimated $R n$ (about $20 \mathrm{~W} \mathrm{~m}^{-2}$ ) is translated into a decrease of $\mathrm{H}$, which is a slight improvement compared to the default simulation (Figure 10d). The decrease of energy excess at the Tchizalamou site (about $50 \mathrm{~W} \mathrm{~m}^{-2}$ ) is distributed equally to LE and $\mathrm{H}$, resulting in a smaller decrease of both. LE is now simulated better, but the LAI-induced improvements for $\mathrm{H}$ are partly neutralized (Figures 11c and 11d). At Demokeya, the improvements of $R n$ only propagate to the sensible heat flux, since LE is limited by water scarcity rather than available energy. As a result, the simulation of $\mathrm{H}$ is significantly improved (Figure 12d). b)

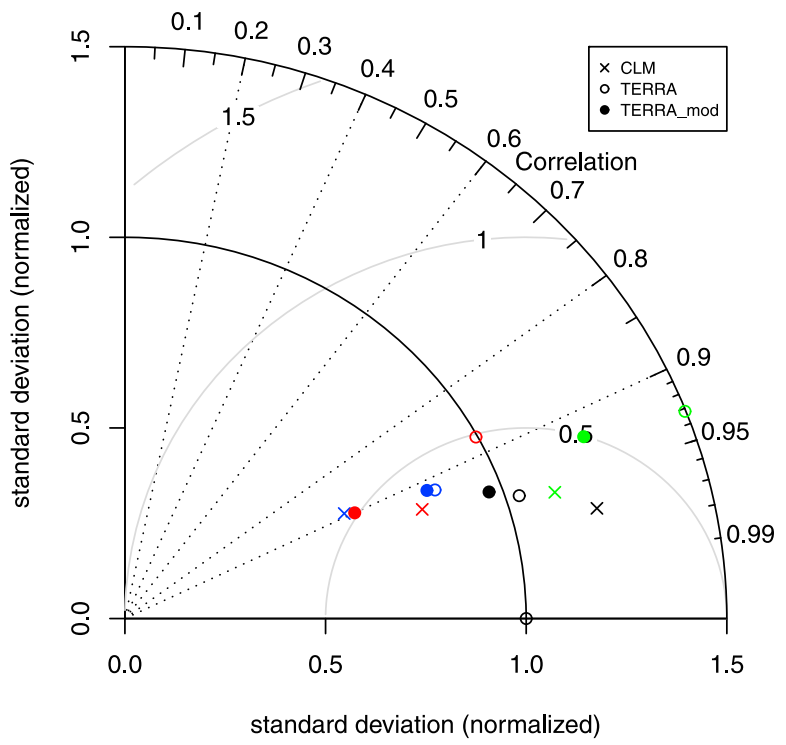

Figure 9. Model performance of all models. Statistics are calculated with hourly observed and simulated latent heat fluxes, including nighttime fluxes. The distance between the plotted point and the 1 value on the $x$ axis is equal to the normalized RMSE, on the polar axis $\mathrm{R}$ is shown, and on the radial axes the proportion of the normalized modeled and observed standard error is given $\left(\sigma_{m} / \sigma_{o}\right)$, which is a measure for variability over- or underestimation. Kissoko: red; Tchizalamou: blue; Demokeya: green; Mongu: black. 

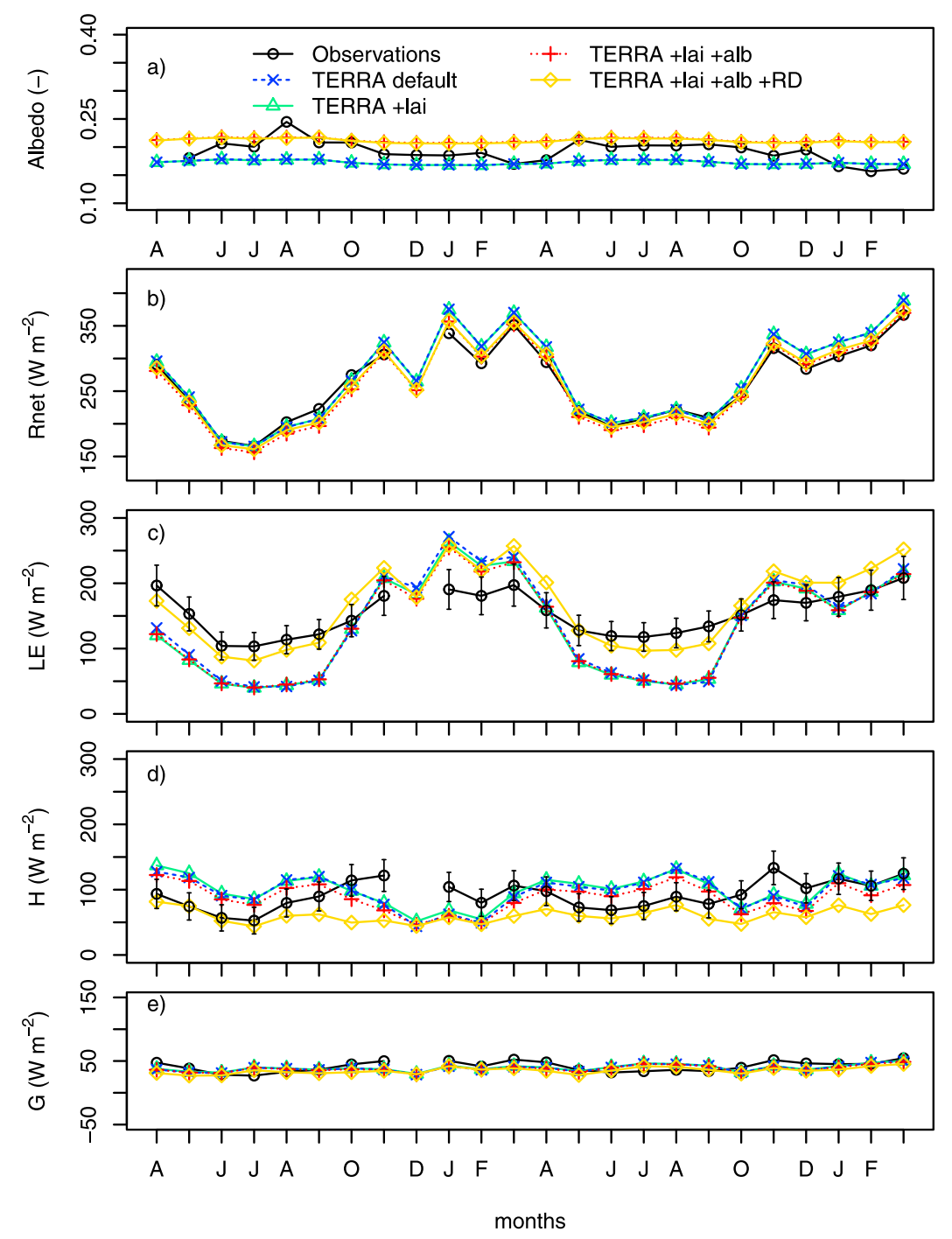

Figure 10. Monthly averaged energy quantities (daytime) at the Kissoko site, 2004-2006: (a) albedo; (b) Rn; (c) LE; (d) H; (e) G. Here +lai stands for modified leaf area index; +alb stands for modified surface albedo; and $+\mathrm{RD}$ stands for modified root depth.

\subsubsection{Root Depth}

[41] Finally the underestimation of LE in the dry season is addressed. During this period, the main controlling factor is transpiration of root zone water by vegetation.

[42] One way to increase model performance is to modify the lower model boundary of TERRA-ML by connecting it to a groundwater aquifer. This replaces the default downward-only free drainage with a two-way interaction including an upward diffusion flux. As a consequence the overall soil moisture content increases year-round, increasing the soil water availability in the root zone and hence preventing LE underestimations in the critical periods. This approach is discussed by Grasselt et al. [2008] and our experiments confirm it with satisfying results (Figures not shown). However, since we lack reliable and continuous soil moisture observations for the Kissoko site, the physical realism of both default and modified hydraulic model configurations are uncertain.

[43] Another approach to improve the model performance is to enlarge the area of water uptake. Rooting depth in
TERRA-ML is parameterized in order to simulate surface fluxes of moisture and energy globally in a realistic way, but is barely meant as a physically correct parameter. In the TERRA look-up tables [Doms et al., 2011] rooting depth of forest/woodland is set to 1 meter (Table 2) which is a significant underestimation compared to observed depths [Canadell et al., 1996; Laclau et al., 2001; Schenk and Jackson, 2002; Christina et al., 2011] but common practice in most present-day land surface schemes [Kleidon and Heimann, 1998]. For tropical evergreen forests, roots are especially important to extract soil water during drier periods in order to maintain a near-potential transpiration rate [Nepstad et al., 1994; Da Rocha et al., 2004]. Since vegetation can only extract soil water from the root zone, root depth is a limiting factor for transpiration and hence for LE.

[44] Both approaches quantitatively succeed in reducing the model biases. However, taking into account both the uncertainty regarding soil hydraulics and the certain underestimation of root depth, the second approach is preferred since it is physically better supported by observations. 

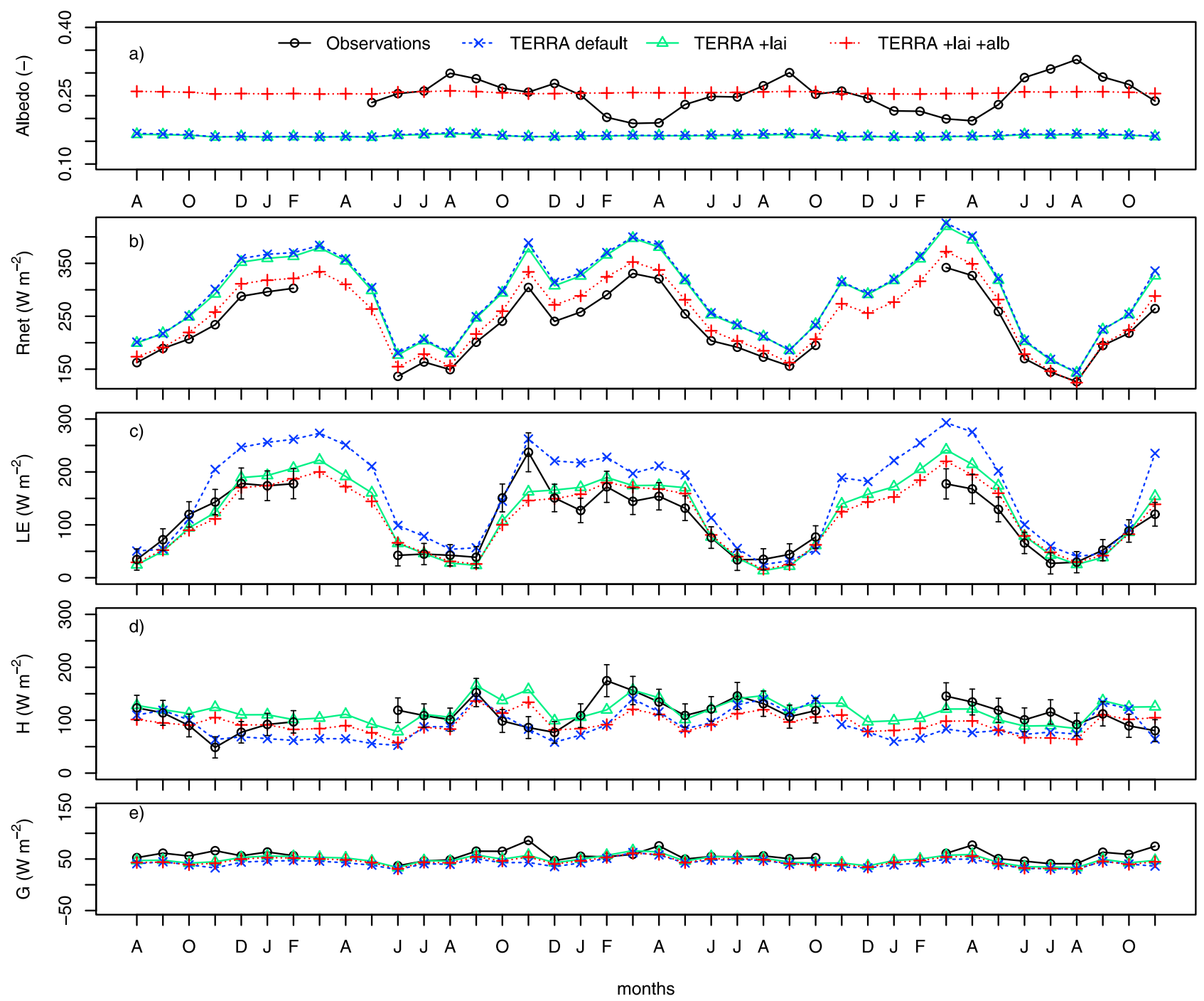

Figure 11. Monthly averaged energy quantities (daytime) at the Tchizalamou site, 2006-2009: (a) albedo; (b) Rn; (c) LE; (d) H; (e) G. Here +lai stands for modified leaf area index, and +alb stands for modified surface albedo.

[45] Root depth of trees is increased to soil depth $(2.40 \mathrm{~m})$ and consequently the roots can extract water from the entire soil column, allowing an enhanced transpiration in dry seasons. Simulations with modified root depth are indicated by yellow lines in Figures 10 and 13. In the Kissoko case, performance improved for both heat fluxes: the dry season LE increased with about $50 \mathrm{~W} \mathrm{~m}^{-2}$, largely removing the underestimations (Figure 10c). The sensible heat flux decreased accordingly (Figure 10d). In the Mongu case, the effect of root depth is limited to the first months of the dry season, after which LE falls back to the values from the default simulation (Figure 13c). The dry period lasts longer compared to Kissoko, which makes the dependency on stored soil water higher.

\subsection{Evaluation on Hourly Timescale}

[46] The combined effect of the modified input parameters on model performance (hereafter called "TERRA mod") is shown in Figure 9 and Table 4. Significant improvements are noticed for the LE in Kissoko (correlation increase from
0.87 to 0.95 and RMSE decrease from 47.5 to 35.26 ) and Tchizalamou (RMSE decrease from 50.57 to 32.83 ), and for the $\mathrm{H}$ in Demokeya (RMSE decrease from 73.84 to 50.55). In other cases, the modified input parameters did not significantly alter the performance. It can be concluded that the overall effect is neutral to positive.

\subsection{Parameterization of Hydraulic Conductivity}

[47] At the Mongu site, the wet-season overestimation of LE by TERRA-ML is not affected by any of the input parameter modifications (Figure 13). Simulated soil hydraulics are examined in order to trace the cause of this pronounced overestimation. The availability of reliable surface soil moisture observations at this flux site allows for a validation of simulated moisture content, hence modifications to model hydraulics can be justified on a physical basis. Figure 14 shows a comparison of simulated and observed soil water content at a depth of $5 \mathrm{~cm}$, i.e., superficial moisture content. The simulation with the improved input parameters (solid yellow line) shows an obvious overestimation during the wet season. 

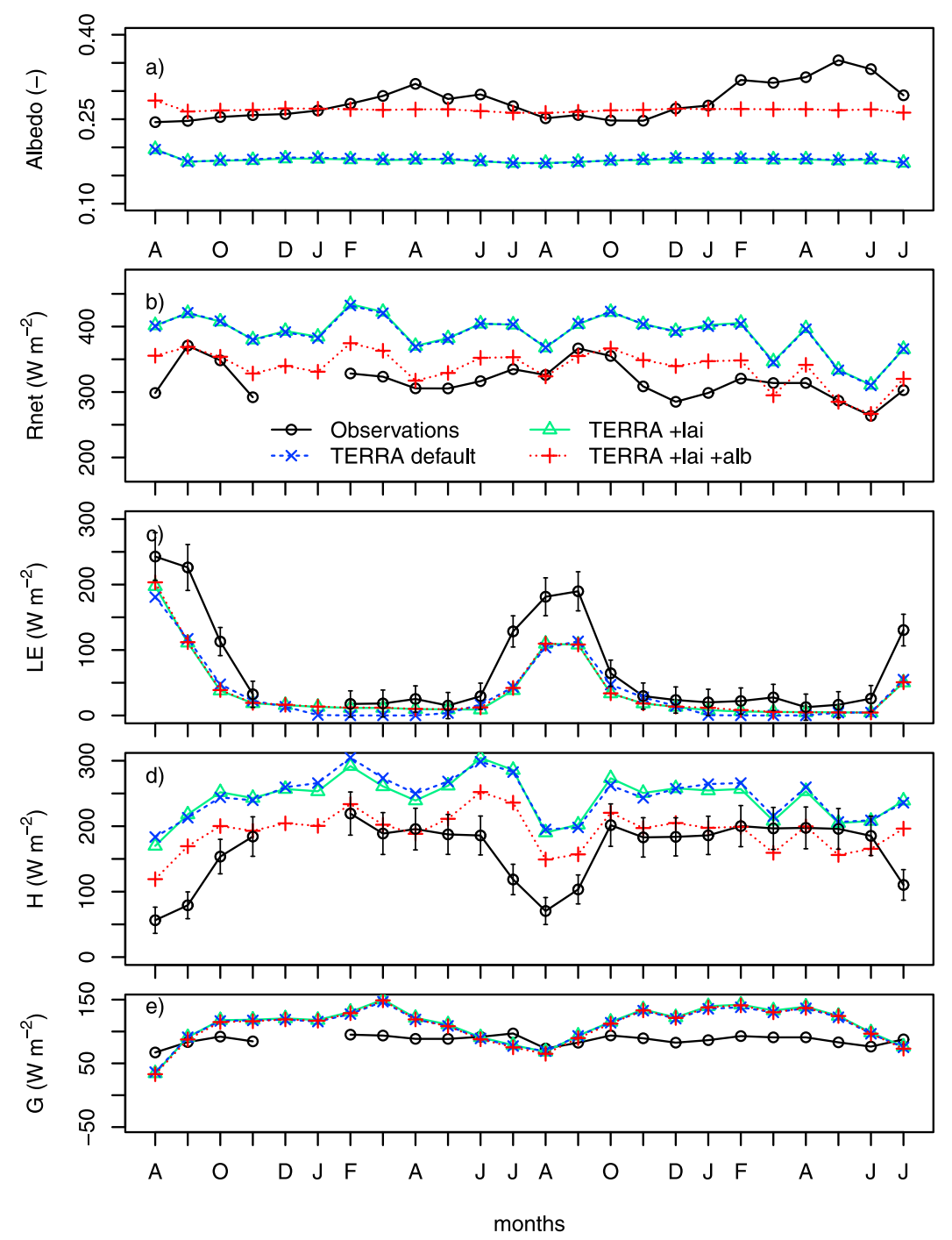

Figure 12. Monthly averaged energy quantities (daytime) at the Demokeya site, 2007-2009: (a) albedo; (b) Rn; (c) LE; (d) H; (e) G. Here +lai stands for modified leaf area index, and +alb stands for modified surface albedo.

[48] Compared to the sandy soils of the other flux sites, the Mongu soil is very well drained, deep, and hydrologically highly conductive. It is located in the "Barotse Sands" from the Kalahari soil group and described by Wolski [1998]. Its characteristics were also confirmed by the flux tower managers of the Mongu site. This difference explains why in reality the water is drained downward much faster compared with the simulations, causing the overestimation of superficial soil water content and hence LE.

[49] The model biases can be reduced by using a different formulation for vertical soil water movements. The hydraulic conductivity $(K)$ in TERRA-ML is by default based on Rijtema's approach, i.e., depending exponentially on soil moisture content [Rijtema, 1969]:

$$
K(\theta)=K_{0} \cdot \exp \left(K_{1} \frac{\theta_{\text {sat }}-\theta}{\theta_{\text {sat }}-\theta_{\text {adp }}}\right)
$$

where $K_{0}$ and $K_{1}$ are the hydraulic conductivity parameters which depend on soil texture, $\theta$ is soil moisture content, $\theta_{\text {sat }}$ is saturated soil moisture content, and $\theta_{\text {adp }}$ is the air dryness point. As an experiment, an alternative linear formulation from Brooks and Corey [1964] is used:

$$
K(\theta)=K_{\text {sat }} \cdot\left(\frac{\theta}{\theta_{\text {sat }}}\right)^{2+3 / b}
$$

where $K_{\text {sat }}$ is the saturated hydraulic conductivity and $b$ is the pore size distribution index which depends on soil texture. As already found by Grasselt et al. [2008], a linear parameterization causes an enhanced downward water flux through the soil column, resulting in a lower superficial soil moisture content (broken purple lines in Figure 14) and a higher base flow. The soil moisture improvement leads to a significant reduction of the LE and consequently $\mathrm{H}$ biases (broken purple lines in Figure 13).

[50] It is however important to stress that this alternative parameterization is a specific solution for a site-specific model bias. Using the same formulation of hydraulic conductivity at the other three flux sites results in general and 

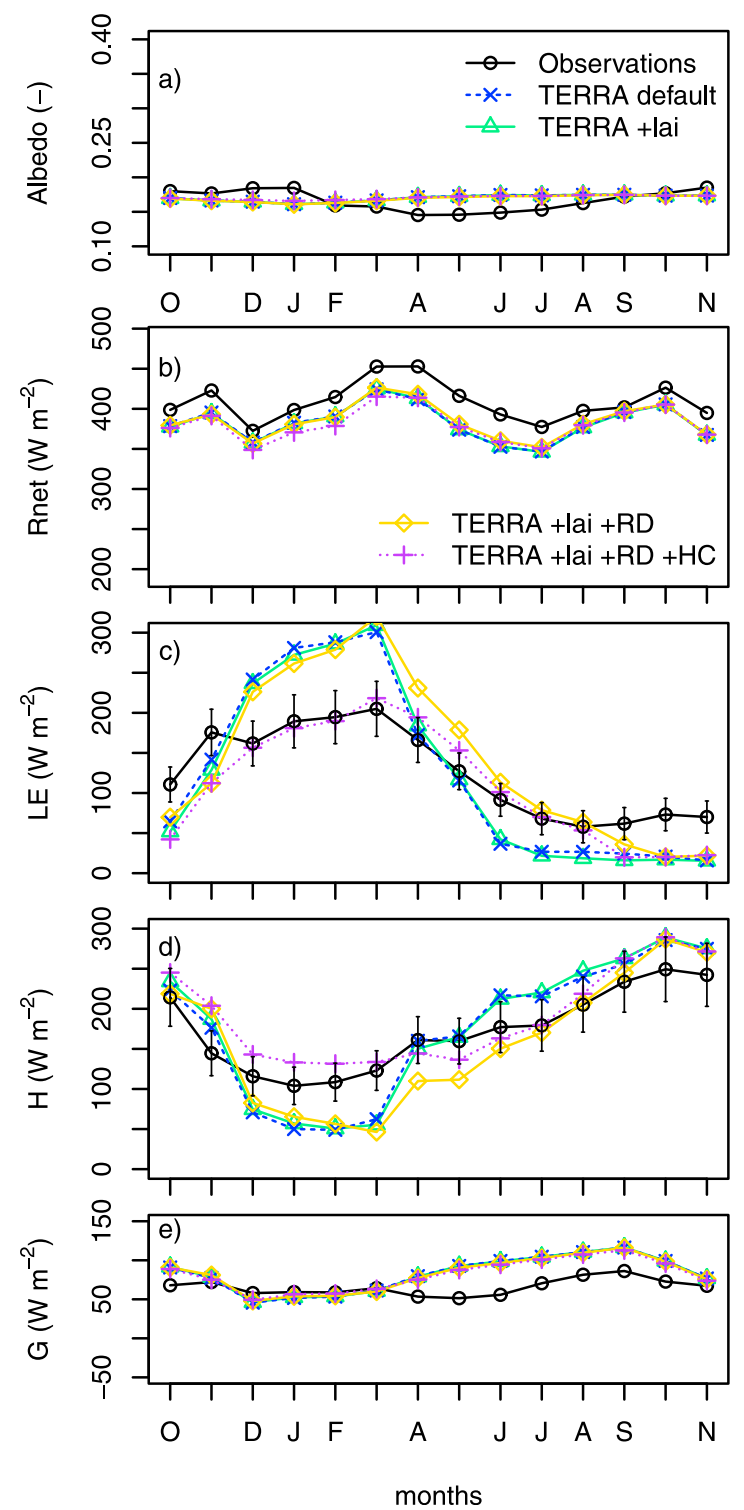

Figure 13. Monthly averaged energy quantities (daytime) at the Mongu site, 2007-2009: (a) albedo; (b) Rn; (c) LE; (d) $\mathrm{H}$; (e) G. Here +lai stands for modified leaf area index; +alb stands for modified surface albedo; $+\mathrm{RD}$ stands for modified root depth; and $+\mathrm{HC}$ stands for modified hydraulic conductivity parameterization.

significant underestimations of LE (Figures not shown). It is not considered as a beneficial modification of TERRA-ML but only used to explain the wet-season overestimation of LE at Mongu. Neither is it a modification of input parameters easy to implement for all grid cells in a coupled atmospheric model, but a site-specific modification of a model parameterization.

\section{Conclusion}

[51] In this study, two SVAT schemes were applied as standalone models at four tropical sites in Africa. The same meteorological forcing data was used for both models. First, the models were tested with their default input parameters. Their performance was assessed and compared by looking to the annual cycle on monthly timescale, and to overall statistics on hourly timescale. Second, three input parameters of TERRA-ML were improved and the effects on the energy balance of all flux sites was quantified.

[52] In their default configuration CLM performs better than TERRA-ML on both timescales at most flux sites. This is represented by lower RMSE values and higher correlation coefficients. Major model deficiencies in TERRA-ML are identified, being an overestimation of LE during the wet season (Tchizalamou), a consistent overestimation of $\mathrm{H}$ (Demokeya), and the failure to capture a sustained evapotranspiration during the dry season (Kissoko, Mongu).

[53] To address these model biases, to test the sensitivity to input parameters and to investigate the true potential performance of TERRA-ML, a series of modifications is applied on the input parameters LAI, surface albedo and root depth.

[54] Firstly, leaf area index in TERRA-ML is generally overestimated compared to observations. This is caused by the relatively simple method of calculating LAI from look-up tables. The replacement of default values with a satellite-based annual cycle only yields an improvement when the LAI difference (i.e., overestimation) is large enough, decreasing biases of LE.

[55] Secondly, substantial biases of simulated albedo (and therefore $R n$ ) are identified. In the surface energy budget, $R n$ is the amount of available energy which is distributed over $\mathrm{LE}, \mathrm{H}$ and $\mathrm{G}$, hence $R n$ biases propagate to one or more of the other budget terms. In TERRA-ML the soil albedo (depending on very few soil classes) as well as the plant albedo are hard-coded constants. Plant and soil albedo in TERRA-ML have been modified to better match the satellite-retrieved surface albedo, resulting in a better simulation of $R n$ and hence of LE and $\mathrm{H}$. The soil albedo in CLM depends on spatially varying soil color (to be provided as input data set) and the plant albedo is related to vegetation phenology (LAI and SAI). LAI and SAI are spatially varying input data sets and based on satellite observations.

[56] Thirdly, in tropical evergreen forests a sufficient amount of soil water has to be available for root uptake during the drier months, when LE depends more on vegetation transpiration. While CLM is successful in doing so, TERRA-ML largely underestimates the dry-season LE. In order to solve the problem of root zone water scarcity,

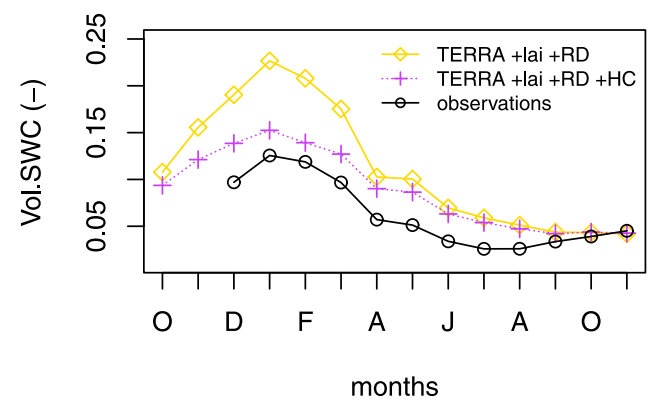

Figure 14. Monthly averaged volumetric soil water content at the Mongu site, 2007-2008. Here +RD stands for modified root depth, and $+\mathrm{HC}$ stands for modified hydraulic conductivity parameterization. Some points are removed due to data gaps. 
different approaches can be used: either 'bringing the water to the roots' or 'bringing the roots to the water', from which the latter is chosen as it is physically better supported by observations. The results indicate that a revision of vegetation parameters is needed for TERRA-ML. This is of course not self-evident since the model is somehow "tuned" to the existing look-up table values (Table 2) which are mainly established by extra-tropical evaluation studies. Plant cover (PC) for the grassland biome in TERRA-ML (Table 2) does not take into account the short dry season; another example of parameters which are mainly tuned for temperate regions.

[57] An unrealistic partitioning of energy by TERRA-ML is identified in the wet season at the Mongu site. The hydraulic parameters of the soil class "sand" in TERRA-ML are not representative for the hydraulically highly conductive "Barotse" soils, limiting the simulated downward water flux (compared to reality). This causes too high superficial soil water contents, explaining the overestimation of LE. The bias is reduced substantially by replacing the default exponential parameterization of hydraulic conductivity with a linear formulation. It is however a very site-specific model bias, and the alternative parameterization is not a general solution since it is not applicable for the other flux sites, where the hydraulic properties of the soil are better represented by the model. The model deficiency was not found in CLM, which uses a linear parameterization [Clapp and Hornberger, 1978] in combination with layer-dependent soil textures.

[58] Based on our findings, some general recommendations for SVAT scheme users and developers are given below. First of all, default input data sets are not always adequate and should be checked for their applicability in the simulated region. Some data sets are composed and calibrated in detail for a certain region (e.g., Europe), whereas in other biomes across the world, parameters may have different values and even have a larger impact (e.g., for tropical rain forests). Without proper region-specific input parameters, simulation performance drops. This was clearly demonstrated by modifying default root depth values in the tropical African evergreen forest, thereby resolving the dry-season underestimation of (evapo) transpiration and hence LE.

[59] Moreover, models show large differences in parameterization complexity. For instance, parameters such as albedo and LAI can be calculated from spatially varying and user-adjustable input data sets (e.g., in CLM, from soil color, plant phenology, etc.) or from a few hard-coded model constants which are supposed to be representative for all vegetation types and biomes (e.g., in TERRA-ML, with fixed plant albedo). In this study, these model constants were modified to observed values, resolving heat flux biases in TERRA-ML on local scale. In more complex SVAT models, spatially explicit input data is used (needed to assure adequate model performance). These complex SVAT models (e.g., CLM) are by default more versatile in its global application on different vegetation types and climates.

[60] Apart from these findings, also computing power and time should be considered. SVAT models with a lower degree of complexity (e.g., TERRA-ML) are much less computationally demanding which leads to faster calculation times in a coupled climate simulation.
[61] Acknowledgments. Field measurements in Kissoko and Tchizalamou were funded by the European Integrated Project Ultra Low $\mathrm{CO}_{2}$ Steelmaking (ULCOS, Contract 515960), by the CARBOAFRICA project, and by the Observatoire de Recherche en Environnement F-ORE-T. Technical assistance was also provided by the CRDPI. Measurements in Demokeya were supported by the Swedish Science Council (2004-3888) and by the EU through the CARBOAFRICA project. Measurements in Mongu were supported by CARBOAFRICA and by institutional funding of the MPI for Biogeochemistry, Jena, Germany. For the simulations we used the infrastructure of the VSC Flemish Supercomputer Center funded by the Hercules Foundation and the EWI Department of the Flemish government. We thank the anonymous reviewers for their valuable comments.

\section{References}

Aguiar, L., J. Costa, G. Fischer, R. Aguiar, A. Costa, and W. Ferreira (2011), Estimate of the atmospheric long wave radiation in forest and pasture area in south west amazon, Rev. Brasileira Meteorol., 26(2), 215-224.

Ardö, J., M. Mölder, B. El-Tahir, and H. Elkhidir (2008), Seasonal variation of carbon fluxes in a sparse savanna in semi arid Sudan, Carbon Balance Manage., 3, 1-18, doi:10.1186/1750-0680-3-7.

Baldauf, M., A. Seifert, J. Förstner, D. Majewski, M. Raschendorfer, and T. Reinhardt (2011), Operational convective-scale numerical weather prediction with the cosmo model: description and sensitivities, Mon. Weather Rev., 139(12), 3887-3905.

Baldocchi, D. (2001), FLUXNET: a new tool to study the temporal and spatial variability of ecosystem-scale carbon dioxide, water vapor, and energy flux densities, Bull. Am. Meteorol. Soc., 82, 2415-2434.

Baldocchi, D., K. Wilson, and L. Gu (2002), How the environment, canopy structure and canopy physiological functioning influence carbon, water and energy fluxes of a temperate broad-leaved deciduous forestan assessment with the biophysical model canoak, Tree Physiol., 22(15-16), 1065-1077.

Bombelli, A., et al. (2009), An outlook on the Sub-Saharan Africa carbon balance, Biogeosciences, 6(10), 2193-2205.

Bonan, G., S. Levis, L. Kergoat, and K. W. Oleson (2002), Landscapes as patches of plant functional types: An integrating concept for climate and ecosystem models, Global Biogeochem. Cycles, 16(2), 1021, doi:10.1029/2000GB001360.

Boone, A., et al. (2004), The Rhone-Aggregation land surface scheme intercomparison project: An overview, J. Clim., 17(1), 187-208.

Brooks, R. H., and A. T. Corey (1964), Hydraulic properties of porous media, Hydrol. Pap., 3(3), 1-27.

Brutsaert, W. (1975), On a derivable formula for long-wave radiation from clear skies, Water Resour. Res., 11(5), 742-744, doi:10.1029/ WR011i005p00742.

Canadell, J., R. Jackson, J. Ehleringer, H. Mooney, O. Sala, and E. Schulze (1996), Maximum rooting depth of vegetation types at the global scale, Oecologia, 108(4), 583-595.

Castaldi, S., A. de Grandcourt, A. Rasile, U. Skiba, and R. Valentini (2010), $\mathrm{CO}_{2}, \mathrm{CH}_{4}$ and $\mathrm{N}_{2} \mathrm{O}$ fluxes from soil of a burned grassland in Central Africa, Biogeosciences, 7, 3459-3471.

Choudhury, B., S. Idso, and R. Reginato (1987), Analysis of an empirical model for soil heat flux under a growing wheat crop for estimating evaporation by an infrared-temperature based energy balance equation, Agric. For. Meteorol., 39(4), 283-297.

Christina, M., J. Laclau, J. Gonçalves, C. Jourdan, Y. Nouvellon, and J. Bouillet (2011), Almost symmetrical vertical growth rates above and below ground in one of the world's most productive forests, Ecosphere, 2(3), $10 \mathrm{pp}$.

Clapp, R., and G. Hornberger (1978), Empirical equations for some soil hydraulic properties, Water Resour. Res., 14(4), 601-604, doi:10.1029/ WR014i004p00601

Collins, W., et al. (2006), The Community Climate System Model version 3 (CCSM3), J. Clim., 19(11), 2122-2143.

Crago, R., and W. Brutsaert (1996), Daytime evaporation and the selfpreservation of the evaporative fraction and the Bowen ratio, J. Hydrol. 178(1-4), 241-255

Da Rocha, H., M. Goulden, S. Miller, M. Menton, L. Pinto, H. de Freitas, and A. e Silva Figueira (2004), Seasonality of water and heat fluxes over a tropical forest in eastern Amazonia, Ecol. Appl., 14(sp4), 22-32.

Davin, E., R. Stöckli, E. Jaeger, S. Levis, and S. Seneviratne (2011), COSMO-CLM2: a new version of the COSMO-CLM model coupled to the Community Land Model, Clim. Dyn., 1, 45.

Dickinson, R. E. (1984), Modeling evapotranspiration for threedimensional global climate models, in Climate Processes and Climate Sensitivity, Geophys. Monogr. Ser., vol. 29, edited by J. E. Hansen and T. Takahashi, pp. 58-72, AGU, Washington, D. C., doi:10.1029/ GM029p0058. 
Dirmeyer, P., A. Dolman, and N. Sato (1999), The pilot phase of the Global Soil Wetness Project, Bull. Am. Meteorol. Soc., 80, 851-878.

Doms, G., et al. (2011), A Description of the Nonhydrostatic Regional COSMO model. Part II: Physical Parameterization, 161 pp., Deutscher Wetterdienst, Offenbach, Germany.

Grasselt, R., D. Schuttemeyer, K. Warrach-Sagi, F. Ament, and C. Simmer (2008), Validation of TERRA-ML with discharge measurements, Meteorol. Z., 17(6), 763-773.

Henderson-Sellers, A., K. McGuffie, and A. Pitman (1996), The project for intercomparison of land-surface parametrization schemes (PILPS): 1992 to 1995 , Clim. Dyn., 12(12), 849-859.

Huemmrich, K., J. Privette, M. Mukelabai, R. Myneni, and Y. Knyazikhin (2005), Time-series validation of MODIS land biophysical products in a Kalahari woodland, Africa, Int. J. Remote Sens., 26(19), 4381-4398.

Idso, S. (1981), A set of equations for full spectrum and 8- to $14-\mu \mathrm{m}$ and 10.5- to $12.5-\mu \mathrm{m}$ thermal radiation from cloudless skies, Water Resour. Res., 17(2), 295-304, doi:10.1029/WR017i002p00295.

Kleidon, A., and M. Heimann (1998), Optimized rooting depth and its impacts on the simulated climate of an atmospheric general circulation model, Geophys. Res. Lett., 25(3), 345-348, doi:10.1029/98GL00034.

Kustas, W., C. Daughtry, and P. Van Oevelen (1993), Analytical treatment of the relationships between soil heat flux/net radiation ratio and vegetation indices, Remote Sens. Environ., 46(3), 319-330.

Laclau, J.-P., M. Arnaud, J.-P. Bouillet, and J. Ranger (2001), Spatial distribution of Eucalyptus roots in a deep sandy soil in the Congo: Relationships with the ability of the stand to take up water and nutrients, Tree Physiol., 21, 129-136.

Lauwaet, D., K. De Ridder, and N. Van Lipzig (2008), The influence of soil and vegetation parameters on atmospheric variables relevant for convection in the Sahel, J. Hydrometeorol., 9, 461-476.

Lawrence, D., et al. (2011), Parameterization improvements and functional and structural advances in version 4 of the Community Land Model, J. Adv. Model. Earth Syst., 3, M03001, doi:10.1029/2011MS000045.

Lawrence, P. J., and T. N. Chase (2007), Representing a new MODIS consistent land surface in the Community Land Model (CLM 3.0), J. Geophys. Res., 112, G01023, doi:10.1029/2006JG000168.

Leeuw, F. D., and E. V. Zantvoort (1997), Mapping of exceedances of ozone critical levels for crops and forest trees in the Netherlands: Preliminary results, Environ. Pollut., 96(1), 89-98.

Majewski, D., D. Liermann, P. Prohl, B. Ritter, M. Buchhold, T. Hanisch, G. Paul, and W. Wergen (2002), The operational global icosahedralhexagonal gridpoint model GME: Description and high-resolution tests, Mon. Weather Rev., 130, 319-338.

Merbold, L., et al. (2009), Precipitation as driver of carbon fluxes in 11 African ecosystems, Biogeosci. Discuss., 5, 4071-4105.

Merbold, L., W. Ziegler, M. Mukelabai, and W. Kutsch (2010), Spatial and temporal variation of $\mathrm{CO}_{2}$ efflux along a disturbance gradient in a miombo woodland in Western Zambia, Biogeosci. Discuss., 7, 5757-5800.

Moncrieff, J., J. Massheder, H. De Bruin, J. Elbers, T. Friborg, B. Heusinkveld, P. Kabat, S. Scott, H. Soegaard, and A. Verhoef (1997), A system to measure surface fluxes of momentum, sensible heat, water vapour and carbon dioxide, J. Hydrol., 188, 589-611.

Nepstad, D., C. Decarvalho, E. Davidson, P. Jipp, P. Lefebvre, G. Negreiros, E. Dasilva, T. Stone, S. Trumbore, and S. Vieira (1994) The role of deep roots in the hydrological and carbon cycles of Amazonian forests and pastures, Nature, 372, 666-669.

Niu, G.-Y., Z.-L. Yang, R. E. Dickinson, L. E. Gulden, and H. Su (2007), Development of a simple groundwater model for use in climate models and evaluation with gravity recovery and climate experiment data, J. Geophys. Res., 112, D07103, doi:10.1029/2006JD007522.

Nouvellon, Y. (2010), Within-stand and seasonal variations of specic leaf area in a clonal Eucalyptus plantation in the Republic of Congo, For Ecol. Manage., 259, 1796-1807.

Nussbaum, S., M. Geissmann, and J. Fuhrer (1995), Ozone exposureresponse relationships for mixtures of perennial ryegrass and white clover depend on ozone exposure patterns, Atmos. Environ., 29(9), 989-995.

Oleson, K., et al. (2004), Technical description of the Community Land Model (CLM), Tech. Note TN-461+STR, 174 pp., Natl. Cent. for Atmos. Res., Boulder, Colo.

Oleson, K., et al. (2007), CLM 3.5 documentation, 34 pp., Natl. Cent. for Atmos. Res., Boulder, Colo.

Pielke, R. (2005), Land use and climate change, Science, 310(5754), $1625-1626$.

Pitman, A. (2003), The evolution of, and revolution in, land-surface schemes designed for climate models, Int. J. Climatol., 23(5), 479-510.

Pitman, A., and A. Henderson-Sellers (1998), Recent progress and results from the project for the intercomparison of landsurface parameterization schemes, J. Hydrol., 212, 128-135.
Reynolds, C. A., T. J. Jackson, and W. J. Rawls (2000), Estimating soil water-holding capacities by linking the Food and Agriculture Organization soil map of the world with global pedon databases and continuous pedotransfer functions, Water Resour. Res., 36(12), 3653-3662, doi:10.1029/2000WR900130.

Rijtema, P. (1969), Soil moisture forecasting, Note 513, 28 pp., Inst. for Land and Water Manage. Res., Wageningen, Netherlands.

Rockel, B., A. Will, and A. Hense (2008), The regional climate model COSMO-CLM (CCLM), Meteorol. Z., 17(4), 347-348.

Saux-Picart, S., C. Ottle, A. Perrier, B. Decharme, B. Coudert, M. Zribi, N. Boulain, B. Cappelaere, and D. Ramier (2009), SEtHyS Savannah: A multiple source land surface model applied to Sahelian landscapes, Agric. For. Meteorol., 149, 1421-1432.

Schenk, H. J., and R. B. Jackson (2002), The global biogeography of roots, Ecol. Monogr., 72(3), 311-328.

Schmetz, J., P. Pili, S. Tjemkes, D. Just, J. Kerkmann, S. Rota, and A. Ratier (2002), An introduction to Meteosat second generation (MSG), Bull. Am. Meteorol. Soc., 83, 977-992.

Schulz, J., et al. (2009), Operational climate monitoring from space: The EUMETSAT Satellite Application Facility on Climate Monitoring (CM-SAF), Atmos. Chem. Phys. 9, 1687-1709.

Schüttemeyer, D., A. Moene, A. Holtslag, and H. De Bruin (2008), Evaluation of two land-surface schemes used in terrains of increasing aridity in West Africa, J. Hydrometeorol., 9, 173-193.

Sellers, P., F. Hall, D. Strebel, R. Kelly, S. Verma, B. Markham, B. Blad, D. Schimel, J. Wang, and E. Kanemasu (1990), The First ISLSCP Field Experiment (FIFE): Experiment operations and interim results, Tech Rep., NASA, Greenbelt, Md.

Sellers, P. J., et al. (1997), Modeling the exchanges of energy, water, and carbon between continents and the atmosphere, Science, 275(5299), 502-509.

Seneviratne, S., D. Lüthi, M. Litschi, and C. Schär (2006), Landatmosphere coupling and climate change in Europe, Nature, 443(7108), 205-209.

Sjöström, M., et al. (2011), Exploring the potential of MODIS EVI for modeling gross primary production across African ecosystems, Remote Sens. Environ., 115(4), 1081-1089.

Snyder, P., C. Delire, and J. Foley (2004), Evaluating the influence of different vegetation biomes on the global climate, Clim. Dyn., 23(3), 279-302.

Stöckli, R., and P. Vidale (2005), Modeling diurnal to seasonal water and heat exchanges at European Fluxnet site, Theor. Appl. Climatol., 80(2), 229-243.

Stöckli, R., D. M. Lawrence, G.-Y. Niu, K. W. Oleson, P. E. Thornton, Z.-L. Yang, G. B. Bonan, A. S. Denning, and S. W. Running (2008), Use of FLUXNET in the Community Land Model development, J. Geophys. Res., 113, G01025, doi:10.1029/2007JG000562.

Taylor, K. E. (2001), Summarizing multiple aspects of model performance in a single diagram, J. Geophys. Res., 106(D7), 7183-7192, doi:10.1029/ 2000JD900719.

Williams, M., et al. (2009), Improving land surface models with FLUXNET data, Biogeosciences, 6, 1341-1359.

Wolski, P. (1998), Remote sensing, land use and hydrotopes in western province, Zambia elements of a groundwater study, Phys. Chem. Earth 23(4), 479-484.

T. Akkermans, M. Demuzere, and N. Van Lipzig, Department of Earth and Environmental Sciences, Katholieke Universiteit Leuven, Celestijnenlaan 200E, B-3001 Heverlee, Belgium. (tom.akkermans@ees.kuleuven.be; matthias. demuzere@ees.kuleuven.be; nicole.vanlipzig@ees.kuleuven.be)

J. Ardö, Department of Physical Geography and Ecosystem Science, Lund University, Sölvegatan 12, SE-223 62 Lund, Sweden. (jonas. ardo@nateko.lu.se)

B. Caquet, A. De Grandcourt, and Y. Nouvellon, UMR Eco and Sols, Centre de Coopération Internationale en Recherche Agronomique pour le Développement (CIRAD), 2 Place Viala, F-34060 Montpellier, France. (agnes.de.grandcourt@gmail.com; yann.nouvellon@cirad.fr)

W. Kutsch, Institut für Agrarrelevante Klimaforschung, Johann Heinrich von Thünen Institut, Bundesallee 50, D-38116 Braunschweig, Germany. (werner.kutsch@vti.bund.de)

D. Lauwaet, Vlaamse Instelling voor Technologisch Onderzoek (VITO), Boeretang 200, B-2400 Mol, Belgium. (dirk.lauwaet@vito.be)

L. Merbold, Grassland Science Group, Institute for Agricultural Sciences (IAS), ETH Zurich, Universitätstrasse 2, CH-8092 Zurich, Switzerland. (lutz.merbold@ipw.agrl.ethz.ch)

G. Vogel, Meteorologisches Observatorium Lindenberg, Deutsche Wetterdienst, Am Observatorium 12, D-15848 Tauche, Germany. (Gerd. Vogel@dwd.de) 